\title{
Bifunctional fused polypeptide inhibits the growth and metastasis of breast cancer
}

\author{
Ai-Ling Liang ${ }^{1-3, *}$ \\ Hai-Li Qian ${ }^{4, *}$ \\ Ting-Ting Zhang ${ }^{1-3}$ \\ Ning Zhoul-3 \\ Hai-Juan Wang ${ }^{4}$ \\ Xi-Ting Men ${ }^{4}$ \\ Wei $\mathrm{Qi}^{5}$ \\ Ping-Ping Zhang ${ }^{6}$ \\ Ming $\mathrm{Fu}^{4}$ \\ Xiao Liang ${ }^{4}$ \\ Chen $\operatorname{Lin}^{4}$ \\ Yong-Jun Liu ${ }^{1-3}$ \\ 'Medical Molecular Diagnostics \\ Key Laboratory of Guangdong, \\ ${ }^{2}$ Department of Biochemistry and \\ Molecular Biology, ${ }^{3}$ Department of \\ Clinical Biochemistry, Guangdong \\ Medical University, Dongguan, \\ Guangdong, ${ }^{4}$ State Key Laboratory of \\ Molecular Oncology, Cancer Institute, \\ Chinese Academy of Medical Sciences, \\ Beijing, ${ }^{5}$ Electroencephalogram Room, \\ ${ }^{6}$ Department of Orthopedics, \\ Guangdong Medical University \\ Affiliated Hospital, Zhanjiang, \\ Guangdong, People's Republic of \\ China \\ *These authors contributed equally \\ to this study
}

Correspondence: Yong-Jun Liu Medical Molecular Diagnostics Key Laboratory of Guangdong, Department of Biochemistry and Molecular Biology, Department of Clinical Biochemistry, Guangdong Medical University,

Dongguan, Guangdong 523808, People's Republic of China

Tel +8676922896350

Fax +8676922896082

Email liuyongjun@gdmc.edu.cn
This article was published in the following Dove Press journal:

Drug Design, Development and Therapy

16 October 2015

Number of times this article has been viewed

\begin{abstract}
Breast cancer is the most common cancer and the leading cause of cancer-related death among women worldwide, with urgent need to develop new therapeutics. Targeted therapy is a promising strategy for breast cancer therapy. Stromal-derived factor-1/CXC chemokine receptor 4 (CXCR4) has been implicated in the metastasis of breast cancer, which renders it to be therapeutic target. This study aimed to evaluate the anticancer effect of fused TATDV1-BH3 polypeptide, an antagonist of CXCR4, and investigate the underlying mechanism for the cancer cell-killing effect in the treatment of breast cancer in vitro and in vivo. This results in a potent inhibitory effect of fused TAT-DV1-BH3 polypeptide on tumor growth and metastasis in nude mice bearing established MDA-MB-231 tumors. Fused TAT-DV1-BH3 polypeptide inhibited the proliferation of MDA-MB-231 and MCF-7 cells but did not affect that of HEK-293 cells. The fused TAT-DV1-BH3 polypeptide colocalized with mitochondria and exhibited a proapoptotic effect through the regulation of caspase- 9 and -3 . Furthermore, the fused TAT-DV1-BH3 polypeptide suppressed the migration and invasion of the highly metastatic breast cancer cell line MDA-MB-231 in a concentration-dependent manner. Notably, the DV1-mediated inhibition of the stromal-derived factor-1/CXCR4 pathway contributed to the antimetastasis effect, evident from the reduction in the level of phosphoinositide 3 kinase and matrix metalloproteinase 9 in MDA-MB-231 cells. Collectively, these results indicate that the apoptosis-inducing effect and migration- and invasion-suppressing effect explain the tumor regression and metastasis inhibition in vivo, with the involvement of caspase- and CXCR4mediated signaling pathway. The data suggest that the fused TAT-DV1-BH3 polypeptide is a promising agent for the treatment of breast cancer, and more studies are warranted to fully elucidate the therapeutic targets and molecular mechanism.
\end{abstract}

Keywords: bifunctional, fused polypeptide, CXCR4, breast cancer, apoptosis, transfer

\section{Introduction}

Breast cancer is the second most common cancer in the world, and it is the most common cancer among women with an estimated 1.67 million new cancer cases diagnosed in 2012, ${ }^{1,2}$ and breast cancer ranks as the fifth cause of death from cancer overall, with a 522,000 deaths globally in 2012. ${ }^{1,2}$ Currently, the chemotherapy for breast cancer is often accompanied with side effects and drug resistance, resulting in therapeutic failure in clinical practice. Thus, there is an urgent need to identify new agents with reduced side effects and improved efficacy for breast cancer treatment.

Compelling evidence shows convincing therapeutic outcomes of targeted therapy for the treatment of breast cancer via promoting cancer cell death and repressing cancer metastasis. ${ }^{3,4}$ Targeting apoptosis, a type of programmed cell death, has been extensively studied in the treatment of cancer through regulating antiapoptotic B-cell lymphoma 2 (Bcl-2) proteins, inhibitor of apoptosis proteins, and murine double-minute 2.,6 Of note, our previous study showed a potent inhibitory effect of a fused peptide on

submit your manuscript | www.dovepress.com 
human colon cancer cells. The fused peptide is composed of BH3 (Bcl-2 homology 3) effector domain from p53 upregulated modulator of apoptosis and targeting domain of transactivator of transcription (TAT) and DV3. ${ }^{7}$ Moreover, emerging evidence suggests that epithelial-mesenchymal transition has been implicated in breast cancer development, growth, and progression, ${ }^{8,9}$ and it has been proposed that epithelial-mesenchymal transition is co-opted by breast cancer cells during their metastatic dissemination from a primary organ to secondary sites. ${ }^{8,9}$ Thus, intervention of this process may represent a novel strategy to prevent breast cancer metastasis.

Interactions between chemokines and their receptors play important roles in many pathological processes, including tumor metastasis. ${ }^{10}$ Membranous CXC chemokine receptor 4 (CXCR4) and its ligand stromal-derived factor-1 (SDF-1 or CXCL12) play an important role in regulating the metastasis of a variety of solid tumors. ${ }^{11} \mathrm{CXCR} 4$ is overexpressed in many cancer tissues, including breast cancer, small-celllung cancer, and colon cancer. ${ }^{12,13}$ Moreover, SDF-1/CXCR4 is involved in the preferential regulation of migration and metastasis of various tumors, including breast cancer cells, to tissues with high expression of SDF-1, including the lymph nodes, lung, liver, and bone marrow. ${ }^{14}$ Therefore, differential SDF-1 and CXCR4 expression is an important biological basis of the SDF-1/CXCR4 signaling pathway that is involved in organ-specific metastasis of tumor cells, and this pathway has become a research hotspot in tumor metastasis.

Therefore, targeting SDF-1/CXCR4 signaling pathway may represent a promising strategy to treat breast cancer. In the present study, a bifunctional fused TAT-DV1-BH3 polypeptide composed of TAT, DV1, and BH3 was generated. TAT was used to ensure that the fused polypeptides efficiently entered cells, DV1 provided CXCR4-binding specificity and served to inhibit metastasis downstream of SDF-1/CXCR4, and BH3 mediated tumor cells apoptosis. ${ }^{7,15}$ We aimed to examine the anticancer effect of the bifunctional fused TAT-DV1-BH3 polypeptide and elucidate the underlying mechanism in the treatment of breast cancer in vivo and in vitro.

\section{Materials and methods Chemical and reagents}

Dulbecco's Modified Eagle's Medium (DMEM), fetal bovine serum, Mito Tracker Red CMXRos, and 4,6-diamidino-2phenylindole (DAPI) were purchased from Thermo Fisher Scientific (Waltham, MA, USA). Protease inhibitor and phosphase inhibitor cocktails were bought from Sigma-Aldrich (St Louis, MO, USA). Cell Counting Kit-8 (CCK-8) was obtained from Dojindo Molecular Technologies, Inc. (Kumamoto, Japan). The primary antibodies against human caspase-3 and caspase- 8 were bought from Cell Signaling Technology, Inc. (Beverly, MA, USA); caspase-9 was obtained from Santa Cruz Biotechnology, Inc. (Dallas, TX, USA); PI3K and MMP-9 were purchased from Abcam, Inc. (Cambridge, UK); and $\beta$-actin was bought from ProteinTech Group, Inc. (Wuhan, People's Republic of China). Super signal-enhanced chemiluminescence was obtained from Applygen Technologies, Inc. (Peking, People's Republic of China).

\section{Synthesizing three fused polypeptides}

The fused TAT-DV1-BH3 polypeptide and two control fused polypeptides were synthesized by GL Biochemistry Ltd (Shanghai, People's Republic of China). These three fused polypeptides were conjugated to fluorescein isothiocyanate (FITC) at the amino ends of the polypeptides. The purity of the three fused polypeptides was $>95 \%$ that was purified by reverse-phase high-performance liquid chromatography. The sequences of these three fused polypeptides were verified by matrix-assisted laser desorption ionization time of flight mass spectrometry.

\section{Cell lines and cell culture}

The human embryonic kidney cell line HEK-293, the highly metastatic human breast cancer cell line MDA-MB-231, and the nonmetastatic human breast cancer cell line MCF-7 were obtained from the American Type Culture Collection (Manassas, VA, USA). MDA-MB-231, MCF-7, and HEK293 cells were cultured in DMEM supplemented with 100 units/mL penicillin, $100 \mu \mathrm{g} / \mathrm{mL}$ streptomycin, and $10 \%$ fetal bovine serum. The cells were maintained at $37^{\circ} \mathrm{C}$ in a $5 \% \mathrm{CO}_{2} / 95 \%$ air-humidified incubator. No ethics statement was required from the institutional review board for the use of these cell lines.

\section{Cell viability assay}

To evaluate the cytotoxicity of these three fused polypeptides in MDA-MB-231, MCF-7, and HEK-293 cells, we used the CCK-8 to measure the survival rate of cells after treatment with $20 \mu \mathrm{M}, 40 \mu \mathrm{M}$, or $80 \mu \mathrm{M}$ of DV1-BH3, TAT-DV1, or TAT-DV1-BH3 for 72 hours. The assay was performed according to the manufacturer's instructions. The absorbance was obtained at wavelengths of $450 \mathrm{~nm}$ and $630 \mathrm{~nm}$ using Synergy H2 Hybrid Microplate Reader (BioTek, Inc., Winooski, 
VT, USA). The experiment was repeated at least three times. Survival rate $(\%)=\left(A_{\text {treated }}-A_{\text {blank }}\right) /\left(A_{\text {control }}-A_{\text {blank }}\right) \times 100$.

\section{Cellular distribution of these three fused polypeptides}

To determine whether the fused polypeptides can enter cells and the intracellular localization, we used a laser scanning confocal microscope (Leica TCS SP5; Leica Microsystems, Wetzlar, Germany) to examine the green fluorescence from the FITC-tagged fused polypeptides as previously described. ${ }^{7,16}$ After treating MDA-MB-231, MCF-7, and HEK-293 with $40 \mu \mathrm{M}$ of DV1-BH3, TAT-DV1, or TATDV1-BH3 for 1 hour, the cells were dyed with Mito Tracker Red CMXRos according to the manufacturer's instructions. Mito Tracker Red CMXRos is a special dye for mitochondria that emits red fluorescence.

\section{Determination of the efficiency for the entry of polypeptides into cells using flow cytometry}

To analyze the efficiency of cellular entry of the fused peptides, we used flow cytometry to measure the green fluorescence from the FITC-tagged fused polypeptides as previously described. ${ }^{7}$ Briefly, MDA-MB-231, MCF-7, and HEK-293 were co-cultured with media containing $20 \mu \mathrm{M}$ of DV1-BH3, TAT-DV1, or TAT-DV1-BH3 for 1 hour. Then, the cells were collected and washed twice with phosphatebuffered saline (PBS). Subsequently, the cells $\left(5 \times 10^{3}\right.$ cells $)$ were subject to analysis by a fluorescence-activated cell sorter (BD FACSCanto ${ }^{\mathrm{TM}}$ II; Becton Dickinson Company, NJ, USA). The percentage of transfected cells in each population was analyzed using FACSDiva 6.1.2 software.

\section{Nuclear morphology examination}

To examine the apoptosis-inducing effect of fused polypeptide, the nuclear morphology was examined via the observation of blue fluorescence from cells stained with DAPI as previously described. ${ }^{7}$ Briefly, MDA-MB-231 and MCF-7 cells were seeded onto coverslips in six-well plates at a density of $1 \times 10^{5}$ cells $/ \mathrm{mL}$ media/well for 24 hours, and then the cells were treated with $80 \mu \mathrm{M}$ fused TATDV1-BH3 polypeptide for 24 hours, 48 hours, or 72 hours. After the treatment, collection cells and staining cells were observed with fluorescence microscopy. Apoptotic cells exhibited typical morphological characteristics of cytoplasmic and nuclear shrinkage, chromatin condensation, and fragmentation.

\section{Cell wound healing assay}

Cell wound healing assay was performed to evaluate the effect of the fused TAT-DV1-BH3 polypeptide on migration of MDA-MB-231 cells. In brief, cells were cultured in 24 -well plates with $2 \times 10^{5}$ cells for 24 hours. When the monolayer cells reach $\sim 90 \%$ confluency, the monolayer of the cells was gently scratched using a $20 \mu \mathrm{L}$ sterile pipette tip, and each well was gently washed twice with DMEM to remove the disturbed cells. Following that, cells were treated with $20 \mu \mathrm{M}, 40 \mu \mathrm{M}$, or $80 \mu \mathrm{M}$ of fused TAT-DV1-BH3 polypeptide for 12 hours, 24 hours, or 48 hours. The healing scratches were observed and photographed.

\section{Transwell invasion assay}

To analyze the effect of fused TAT-DV1-BH3 polypeptide on the invasion of the highly metastatic human breast cancer cell line MDA-MB-231, we employed a Transwell assay (containing 8.0- $\mu \mathrm{m}$ diameter membranes) according to the manufacturer's instructions. Briefly, MDA-MB-231 cells suspended in serum-free media placed in the upper compartment of $8-\mu \mathrm{m}$-pore transwell with Matrigel coated basement membrane. Cells were allowed to migrate with $20 \mu \mathrm{M}, 40 \mu \mathrm{M}$, or $80 \mu \mathrm{M}$ fused TAT-DV1-BH3 polypeptide containing media or corresponding control media in the upper compartment. After 1-hour incubation, the lower DMEM was changed to $600 \mu \mathrm{L}$ of fresh DMEM with $0.1 \mu \mathrm{g} / \mathrm{mL}$ hSDF-1 $\beta$, and the cells were cultured for 24 hours. The noninvading cells were removed from the interior of the inserts, and then the invasive cells on the lower surface of the membrane were stained and imaged under microscope. The invasive cells were finally quantitated.

\section{Western blotting assay}

The protein expression level was determined using Western blotting assays. MDA-MB-231 cells were treated with $20 \mu \mathrm{M}, 40 \mu \mathrm{M}$, or $80 \mu \mathrm{M}$ fused TAT-DV1-BH3 polypeptide for 72 hours, and the cell samples were lysed with the RIPA buffer containing the protease inhibitor and phosphase inhibitor cocktails. Protein concentrations were measured by Pierce $^{\mathrm{TM}}$ BCA protein assay kit (Thermo Fisher Scientific). Equal amount of protein sample $(100 \mu \mathrm{g})$ was electrophoresed on $10 \%$ sodium dodecyl sulfate polyacrylamide gel electrophoresis mini-gel after thermal denaturation for 5 minutes at $95^{\circ} \mathrm{C}$. Proteins were transferred onto nitrocellulose membrane at $100 \mathrm{~V}$ for 2 hours at $4^{\circ} \mathrm{C}$. Membranes were probed with indicated primary antibody overnight at $4^{\circ} \mathrm{C}$ and then blotted with respective secondary antibody. Visualization was performed using X-ray file with enhanced 
chemiluminescence substrate, and the blots were analyzed using Image Lab 3.0 (Bio-Rad Laboratories Inc., Hercules, CA, USA). Protein level was normalized to the matching densitometric value of internal control.

\section{Animal experiments}

A total number of 40 female athymic $\mathrm{Nu} / \mathrm{Nu}$ nude mice (4-5 weeks, 12-14 g, NU-Foxn ${ }^{\text {nu }}$ ) were purchased from Charles River Laboratories (Burlington, MA, USA). All animals were housed in plastic cages containing wood shaving and cotton bedding and maintained in a room at $22^{\circ} \mathrm{C}-25^{\circ} \mathrm{C}$ with a 12 -hour light/dark cycle with free access to standard laboratory diet and water. All mice were allowed to acclimate for 12-14 days prior to experiments. The animal study protocol was approved by the Institutional Animal Care and Use Committee at the Guangdong Medical University.

Xenograft tumors were established by sc injection of $1 \times 10^{7}$ MDA-MB-231 cells into the fat pad of the right second breast of five female nude mice. ${ }^{17}$ The tumors were removed from the mice and cut into $2 \times 2 \times 2 \mathrm{~mm}$ sections, when they reached the volume of $\sim 1 \mathrm{~cm}^{3}$. These tumor sections were implanted into eight nude mice. Once the transplanted tumors reached $\sim 1 \mathrm{~cm}^{3}$ in volume, the tumors were cut into $2 \times 2 \times 2 \mathrm{~mm}$ sections and then were implanted into 28 nude mice. One week after implantation, all nude mice were divided into four groups $(n=7)$. The mice received the treatment of PBS, DV1-BH3, TAT-DV1, and TAT-DV1-BH3 (1.2 mM/100 $\mu \mathrm{L}$, once every 2 days) by intratumoral injection. The tumor volume and weight of the nude mice were measured once every 2 days. The tumor volumes were calculated, and the tumors were weighed. On the 23 rd day after the first injection, all mice were euthanized, and the tumors of all livers with metastasis were obtained and subject to pathological analysis.

\section{Statistical analysis}

The data are presented as mean \pm standard deviation. Multiple comparisons were evaluated by one-way analysis of variance followed by Tukey's multiple comparison. A value of $P<0.05$ was considered statistically significant.

\section{Results Synthesis of three fused polypeptides}

We first designed and synthesized three fused polypeptides that were speculated to be antagonists for CXCR4. The sequences, purity, and quality of the fused polypeptides met the experimental requirements (Table 1). The sequences of these three fused polypeptides were as follows: TAT-DV1BH3 (RRRQR RKKRG GGGLG $\underline{\text { ASW HRPDK CCLGY }}$ QKRRL PGGGLRRMA DDLNA QY), TAT-DV1 (RRRQR RKKRG GGGLG $\underline{A S W}$ HRPDK CCLGY QKRRL P), and DV1-BH3 (LGASW HRPDK CCLGY QKRRL PGGGLRRMA DDLNA QY). Underlined letters indicated D-conformation amino acids. The molecular weight was 6,156.11, 4,537.30, and 4,606.28 for TAT-DV1-BH3, TAT-DV1, and DV1-BH3, respectively. The purity was $96.32 \%, 96.96 \%$, and $95.29 \%$ for TAT-DV1-BH3, TAT-DV1, and DV1-BH3, respectively. Subsequently, we explored the biological functions of these fused polypeptides and the underlying mechanism in vitro and in vivo models.

\section{TAT-DVI-BH3 polypeptide inhibits the growth of breast cancer lines}

We examined the effect of fused polypeptides on cell growth using CCK-8. MDA-MB-231, MCF-7, and HEK-293 cells were explored. Cells were treated with DV1-BH3, TAT-DV1, or TAT-DV1-BH3 at $20 \mu \mathrm{M}, 40 \mu \mathrm{M}$, or $80 \mu \mathrm{M}$ for 72 hours. As shown in Figure 1, DV1-BH3 and TAT-DV1 did not inhibit the growth of MDA-MB-231, MCF-7, and HEK-293 cells. However, TAT-DV1-BH3 concentration dependently inhibited the growth of MDAMB-231 and MCF-7 cells and remarkably suppressed the growth of cancer cells with survival rate of $28.67 \%$ and $36.97 \%$ for MDA-MB-231 and MCF-7 cells at $80 \mu \mathrm{M}$, respectively ( $P<0.05$; Figure 1 and Table 2$)$. It represented growth inhibition of $71.33 \%$ and $63.03 \%$ in MDA-MB-231 and MCF-7 cells, respectively. Notably, TAT-DV1-BH3 did not exhibit marked inhibitory effect on the growth of HEK-293 cells. Taken together, these results indicate that only the fused TAT-DV1-BH3 polypeptide significantly inhibits the growth of the two breast cancer cell lines and that

Table I Parameters of three fused polypeptides

\begin{tabular}{|c|c|c|c|c|}
\hline Name & Peptide sequence & MW & Qty (mg) & Purity \\
\hline TAT-DVI-BH3 & FITC RRRQRRKKRG GGG d(LGASWHRPDKCCLGYQKRRLP) GGG LRRMADDLNAQY & $6,156.11$ & 100.1 & $96.32 \%$ \\
\hline TAT-DVI & FITC RRRQRRKKRG GGG d(LGASWHRPDKCCLGYQKRRLP) & $4,537.30$ & 80.0 & $96.96 \%$ \\
\hline DVI-BH3 & FITC d(LGASWHRPDKCCLGYQKRRLP) GGG LRRMADDLNAQY & $4,606.28$ & 81.4 & $95.29 \%$ \\
\hline
\end{tabular}

Abbreviations: $\mathrm{BH} 3, \mathrm{Bcl}-2$ homology 3; TAT, transactivator of transcription; MW, molecular weight; Qty, quality. 
MDA-MB-231 cells

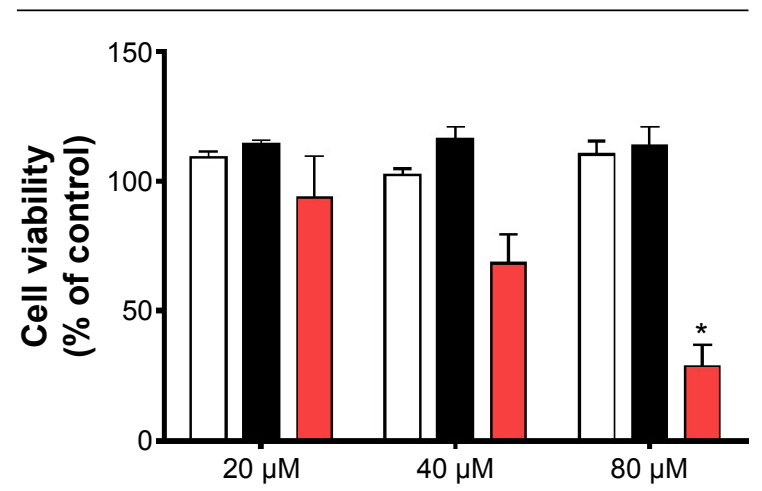

MCF-7 cells

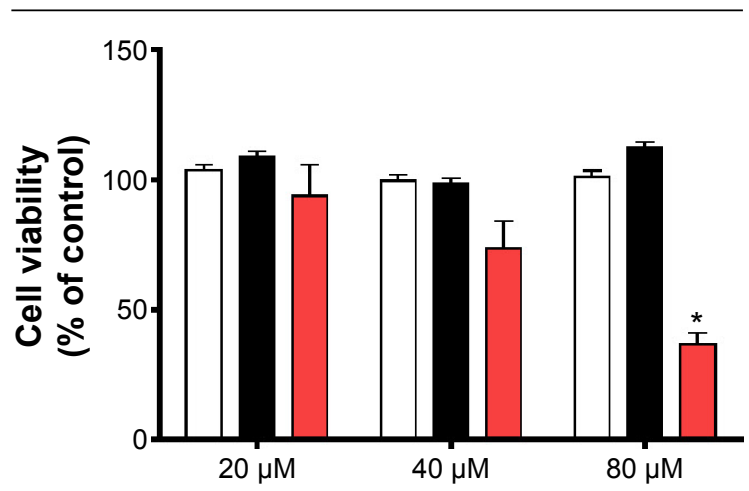

HEK-293 cells

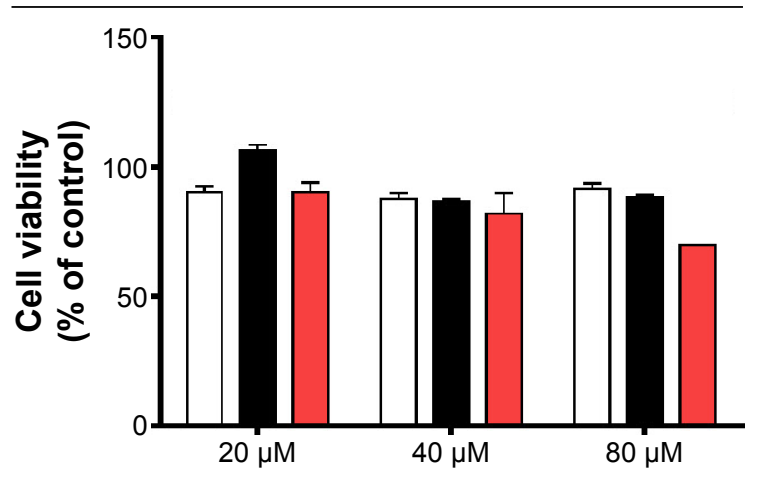

\section{$\square$ DV1-BH3 $\square$ TAT-DV1 $\square$ TAT-DV1-BH3}

Figure I The effects of DVI-BH3, TAT-DVI, and TAT-DVI-BH3 on the viability of MDA-MB-23I, MCF-7, and HEK-293 cells.

Notes: MDA-MB-23I, MCF-7, and HEK-293 cells were treated with DVI-BH3, TAT-DVI, and TAT-DVI-BH3 at $20 \mu \mathrm{M}, 40 \mu \mathrm{M}$, or $80 \mu \mathrm{M}>72$ hours, and the cell growth was analyzed using the CCK-8 kit. Data are expressed as mean \pm SD of three independent experiments. $* P<0.05$ by one-way ANOVA.

Abbreviations: $\mathrm{BH} 3, \mathrm{Bcl}-2$ homology 3; TAT, transactivator of transcription; CCK-8, cell-counting kit; SD, standard deviation; ANOVA, analysis of variance.

TAT-DV1-BH3 does not inhibit the growth of nontumor cell HEK-293 cells.

\section{TAT-DVI-BH3 polypeptide colocalizes with mitochondria in the cytoplasm}

To observe the cellular localization of these three polypeptides, laser scanning confocal microscopic examination was performed to measure the green fluorescence from the FITCtagged polypeptides and the red fluorescence from mitochondria stained with the specific tracking dye Mito Tracker ${ }^{\circledR}$
Red CMXRos. MDA-MB-231, MCF-7, and HEK-293 cells were incubated with $40 \mu \mathrm{M}$ TAT-DV1-BH3, TAT-DV1, or DV1-BH3 for 1 hour, and the fluorescence was examined (Figure 2A-C). The fused TAT-DV1 and TAT-DV1-BH3 polypeptides entered into cells and largely distributed in the cytoplasm, due to the TAT sequence (Figure 2A-C). Notably, these two fused polypeptides containing TAT were found to colocalize with mitochondria in MDA-MB-231, MCF-7, and HEK-293 cells (Figure 2A-C). However, due to the lack of TAT sequence, the DV1-BH3 polypeptide was unable

Table 2 Survival rates of three cell lines with different concentrations of three polypeptides (mean \pm SD\%)

\begin{tabular}{|c|c|c|c|c|c|c|c|c|c|}
\hline \multirow{2}{*}{$\begin{array}{l}\text { Polypeptides } \\
\text { cell }\end{array}$} & \multicolumn{3}{|c|}{ TAT-DVI-BH3 $(\mu \mathrm{M})$} & \multicolumn{3}{|c|}{ TAT-DVI $(\mu \mathrm{M})$} & \multicolumn{3}{|c|}{ DVI-BH3 $(\mu \mathrm{M})$} \\
\hline & 20 & 40 & 80 & 20 & 40 & 80 & 20 & 40 & 80 \\
\hline MDA-MB-23I & $93.81 \pm 15.84$ & $68.29 \pm 11.21$ & $28.67 \pm 8.22 *$ & $1 \mid 4.24 \pm 1.54$ & $116.08 \pm 4.95$ & $113.59 \pm 7.28$ & $109.37 \pm 1.95$ & $102.47 \pm 2.03$ & $110.39 \pm 5.13$ \\
\hline MCF-7 & $93.88 \pm 11.97$ & $73.70 \pm 10.38$ & $36.97 \pm 4.22^{*}$ & $108.60 \pm 2.22$ & $98.38 \pm 2.16$ & $112.41 \pm 1.97$ & $103.76 \pm 1.99$ & $99.55 \pm 2.53$ & $100.89 \pm 2.53$ \\
\hline HEK-293 & $90.31 \pm 3.60$ & $81.80 \pm 7.83$ & $69.85 \pm 8.02$ & $106.22 \pm 2.11$ & $86.47 \pm 1.01$ & $88.28 \pm 1.02$ & $90.37 \pm 2.02$ & $87.62 \pm 2.28$ & $91.38 \pm 2.03$ \\
\hline
\end{tabular}

Note: $* P<0.05$.

Abbreviations: $\mathrm{BH} 3, \mathrm{Bcl}-2$ homology 3; TAT, transactivator of transcription; SD, standard deviation. 
A

TAT-DV1-BH3

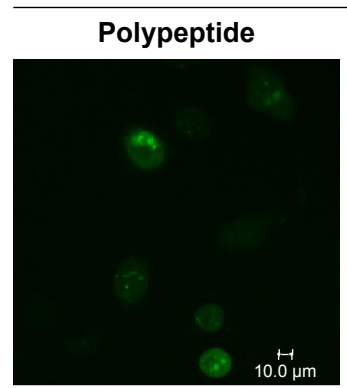

$10.0 \mathrm{~mm}$

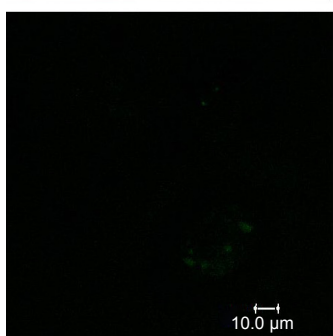

DV1-BH3

B

TAT-DV1-BH3

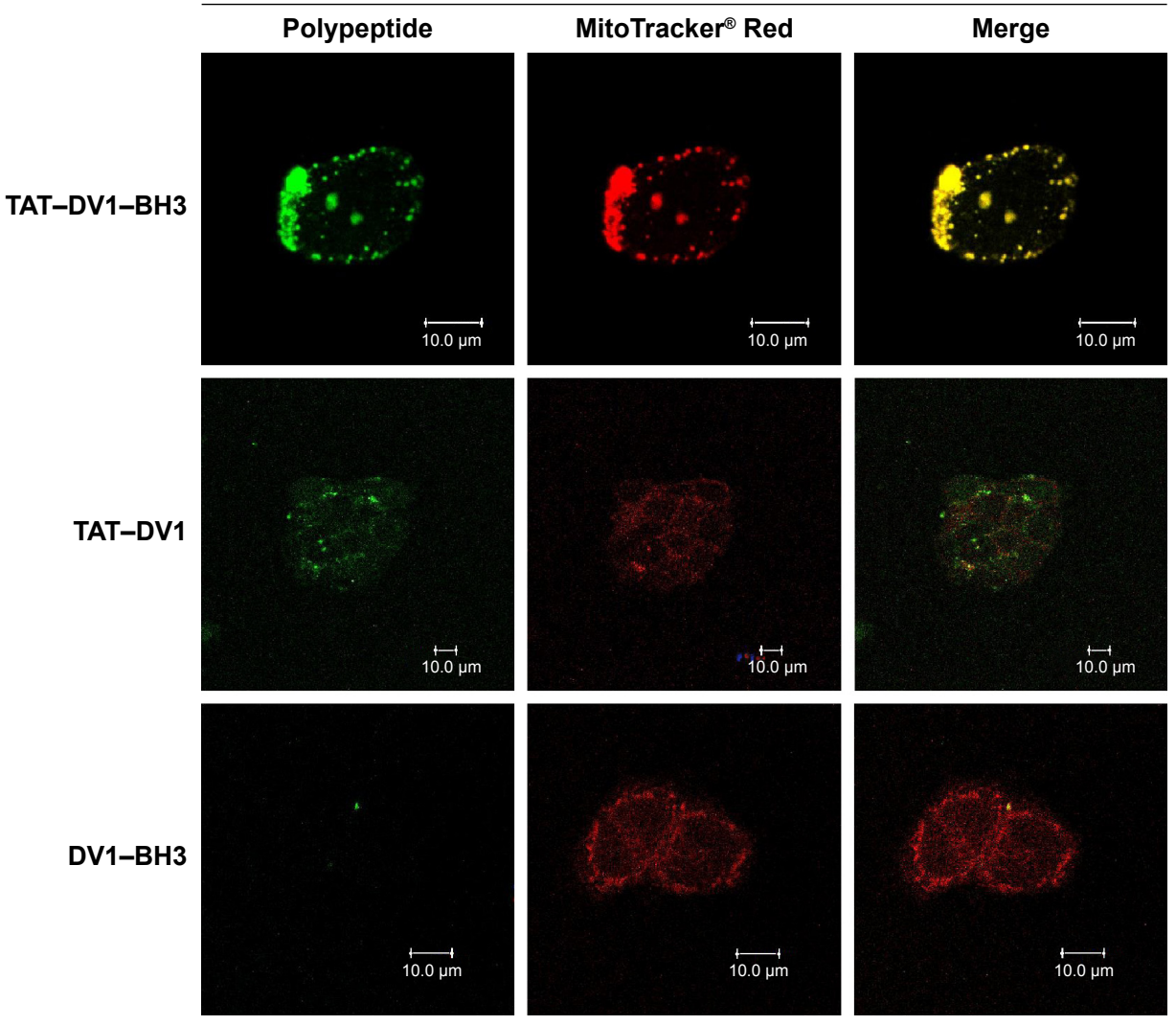

TAT-DV1
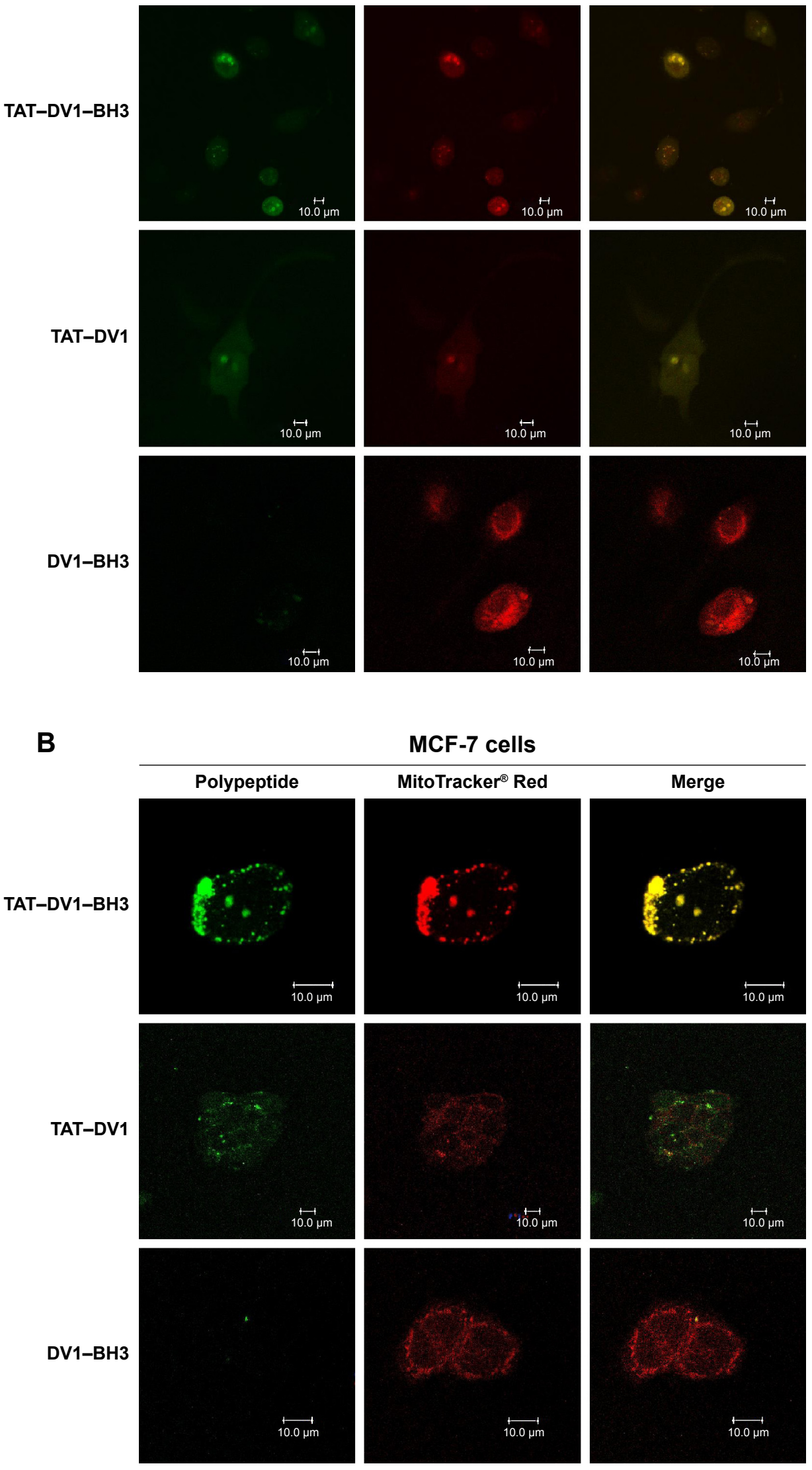

$10.0 \mu \mathrm{m}$

MCF-7 cells

MitoTracker ${ }^{\circledR}$ Red
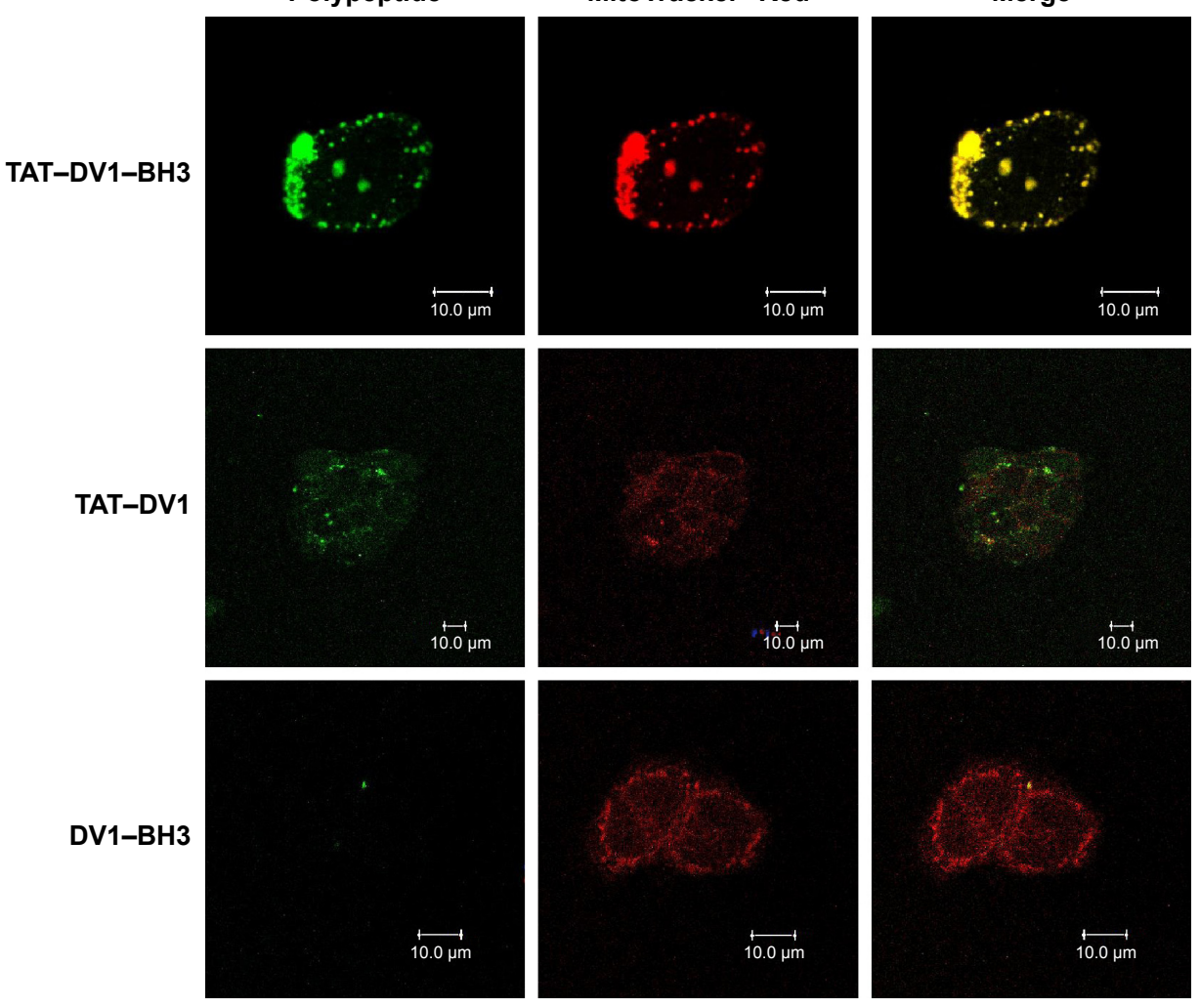

Merge
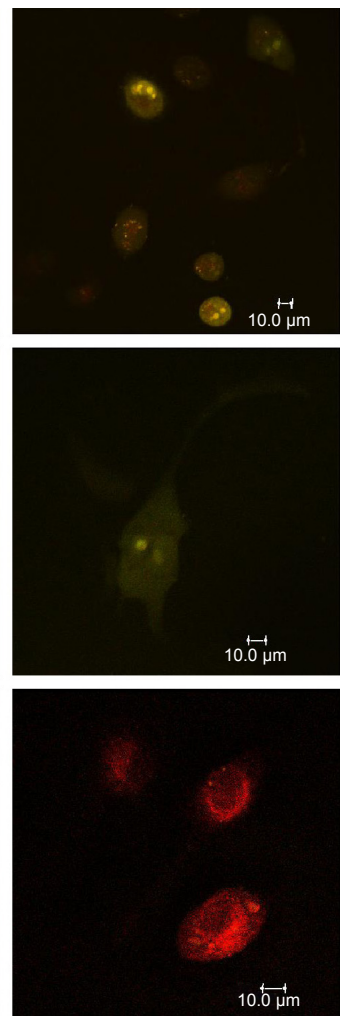

$10.0 \mathrm{ptm}$

Figure 2 (Continued) 


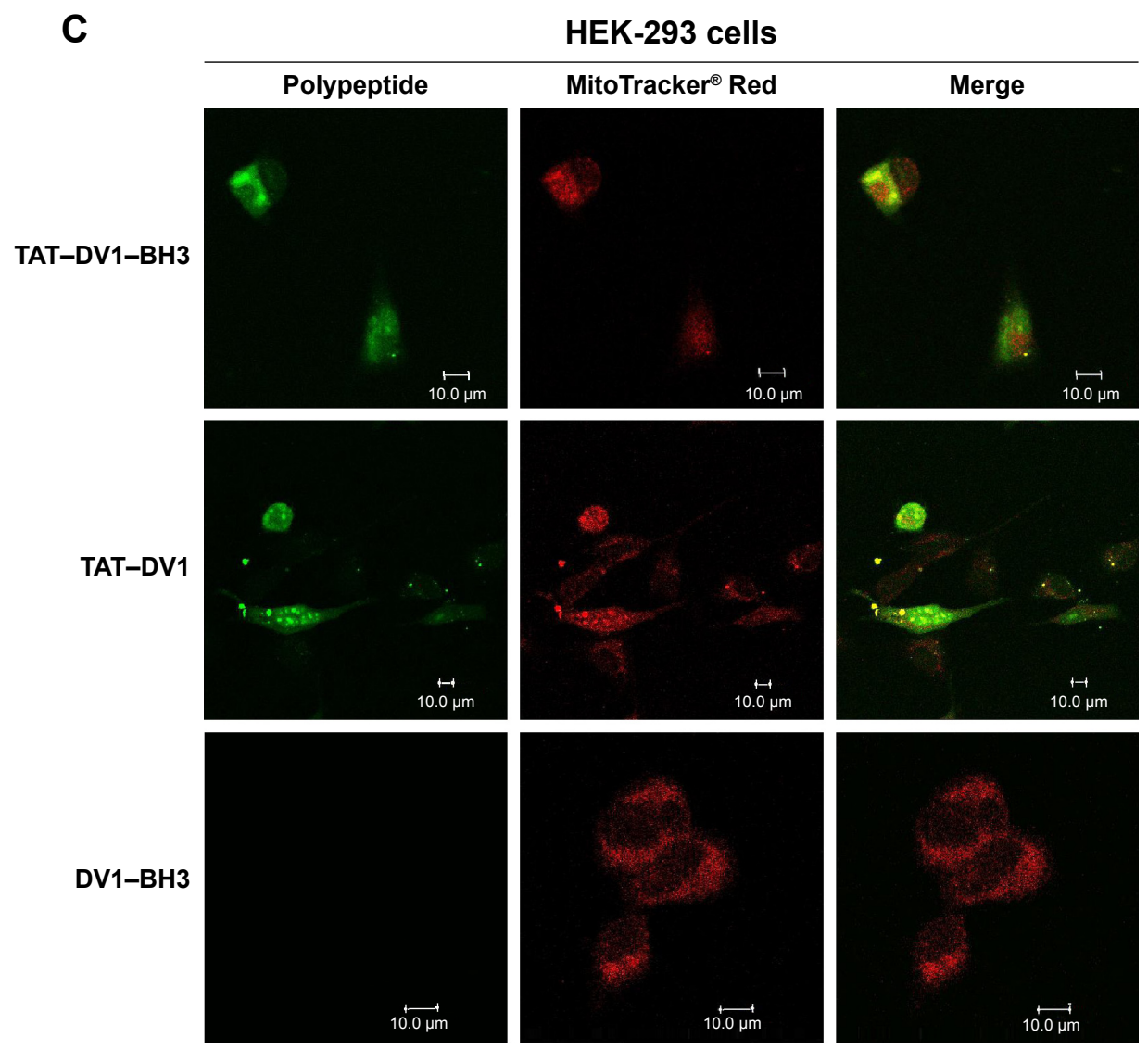

Figure 2 The colocalization of DVI-BH3, TAT-DVI, and TAT-DVI-BH3 in MDA-MB-23I, MCF-7, and HEK-293 cells.

Notes: The fused polypeptides and the mitochondria were observed using laser scanning confocal microscopy. MDA-MB-23I (A), MCF-7 (B), and HEK-293 (C) cells were treated with $40 \mu \mathrm{M}$ DVI-BH3, TAT-DVI, or TAT-DVI-BH3 for I hour and washed with PBS, then the cells were stained with Mito Tracker Red CMXRos. The green fluorescence was from the polypeptides and the red fluorescence was from the mitochondria. Scale bar, $10 \mu \mathrm{m}$.

Abbreviations: $\mathrm{BH} 3, \mathrm{Bcl}-2$ homology 3; TAT, transactivator of transcription; PBS, phosphate-buffered saline.

to enter into cells after co-culturing with cells for 1 hour, evident from the single observation of red fluorescence (Figure 2A-C).

\section{Fused polypeptides with TAT sequence efficiently enter into cells}

To further evaluate the efficiency of fused polypeptide entry into cells, the intracellular level of fluorescence was examined using flow cytometry. MDA-MB-231, MCF-7, and HEK-293 cells were incubated with $20 \mu \mathrm{M}$ TAT-DV1-BH3, TAT-DV1, or DV1-BH3 for 1 hour, and the fluorescence was examined (Figure 3). The fused TAT-DV1-BH3 polypeptide efficiently entered into the three cell lines. The percentage was $98.3 \%$, 91.7\%, and 92.4\% in HEK-293, MDA-MB-231, and MCF-7 cells, respectively (Figure 3 ). The TAT-DV1 polypeptide also exhibited a high transfection efficiency with the percentage of 99.9\%, 96.2\%, and 83.4\% in HEK-293, MDA-MB-231, and MCF-7 cells, respectively (Figure 3 ). However, there was a very low transfection efficiency for DV1-BH3 in these three cell lines. The percentage was $0.5 \%, 0.4 \%$, and $1.7 \%$ in HEK293, MDA-MB-231, and MCF-7 cells, respectively (Figure 3).
In aggregate, the results indicate that the TAT sequence is essential for the entry of polypeptide into the cells.

\section{TAT-DVI-BH3 polypeptide exerts proapoptotic effect in MDA-MB-23I cells}

Since we have observed the inhibitory effect on tumor growth and tumor cell proliferation and intracellular localization of TAT-DV1-BH3 polypeptide, we further investigated the underlying mechanism for the cancer cell killing effect. First, we examined the nuclei morphology when MDAMB-231 cells were exposed to TAT-DV1-BH3 polypeptide for 24 hours, 48 hours, or 72 hours using fluorescence microscopy. MDA-MB-231 cells exhibited intact nuclear membranes and clear chromatin in the absence of TATDV1-BH3 polypeptide, which is indicative of normal nuclear morphology (Figure 4). There was a dramatic alteration in the nuclear morphology with apoptotic features when cells were exposed to TAT-DV1-BH3 polypeptide. In particular, the nuclei exhibited the characteristics of crimpled nuclear membrane and condensed chromatin after 48-hour exposure to fused TAT-DV1-BH3 polypeptide (Figure 4). Furthermore, 


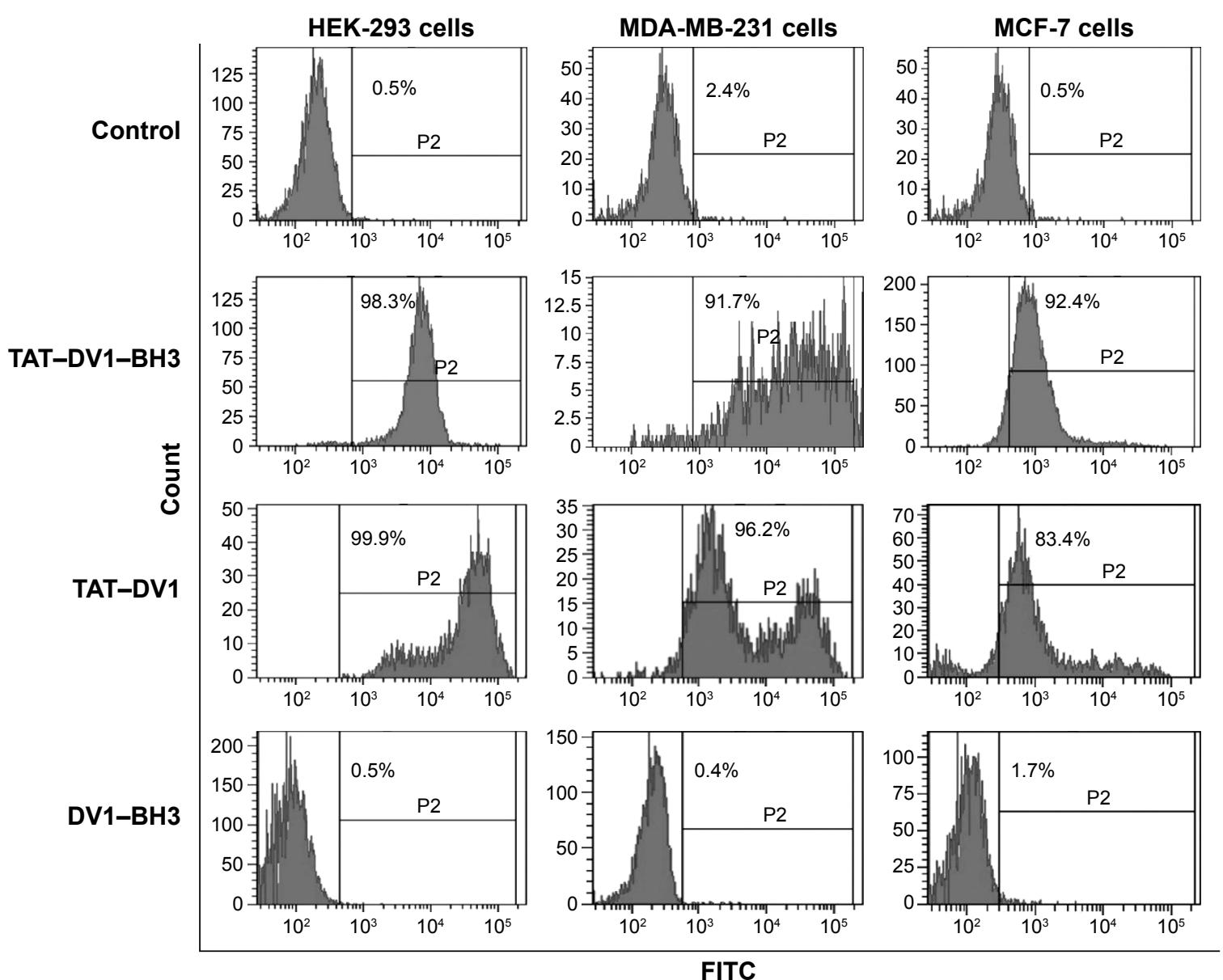

Figure 3 The transfection rate of DVI-BH3, TAT-DVI, and TAT-DVI-BH3 in MDA-MB-23I, MCF-7, and HEK-293 cells.

Notes: The histogram of the transfection rate of the three fused polypeptides. Cells were exposed to $20 \mu M$ DVI-BH3, TAT-DVI, or TAT-DVI-BH3 for I hour and washed with PBS. Then, the cells were subject to flow cytometry. The number of green fluorescent cells was quantified, and the transfection rates were calculated. Abbreviations: $\mathrm{BH} 3, \mathrm{Bcl}-2$ homology 3; TAT, transactivator of transcription; PBS, phosphate-buffered saline.

the nuclei exhibited apoptotic features of significant membrane breakage, chromatin condensation, and fragmentation when MDA-MB-231 cells were incubated with fused TATDV1-BH3 polypeptide for 72 hours (Figure 4). Collectively, the alterations in the nuclear morphology indicate that fused TAT-DV1-BH3 polypeptide possesses proapoptotic effect in MDA-MB-231 cells. Similar results were obtained in MCF-7 cells as well (data not shown).

We further studied the underlying mechanism for the apoptosis-inducing effect of fused TAT-DV1-BH3 polypeptide. The effect of fused TAT-DV1-BH3 polypeptide on the expression of procaspase- $8,-9$, and -3 and active caspase- 8 and -9 was examined using Western blotting assay (Figure 5A and B). MDA-MB-231 cells were treated with fused TAT-DV1-BH3 polypeptide at $20 \mu \mathrm{M}, 40 \mu \mathrm{M}$, and $80 \mu \mathrm{M}$ for 72 hours, resulting in a remarkable alteration in the level of these key caspases involved in apoptosis pathway. TAT-DV1-BH3 decreased $45.6 \%, 30.4 \%$, and $64.5 \%$ in the level of procaspase- 8 without evident changes in the level of caspase- 8 at the concentrations of $20 \mu \mathrm{M}, 40 \mu \mathrm{M}$, and $80 \mu \mathrm{M}$, compared to the control, respectively $(P<0.01$ or 0.001 ; Figure $5 \mathrm{~A}$ and $\mathrm{B}$ ). Also, there was a concentrationdependent decrease in the level of procaspase- 9 and increase in caspase-9 $(P<0.05$ or 0.001 ; Figure $5 \mathrm{~A}$ and $\mathrm{B})$. In comparison to the control, there was a $21.5 \%, 59.7 \%$, and $94.8 \%$ reduction in the level of procaspase- 9 when treated with fused TAT-DV1-BH3 polypeptide at $20 \mu \mathrm{M}, 40 \mu \mathrm{M}$, and $80 \mu \mathrm{M}$, respectively, and $80 \mu \mathrm{M}$ fused TAT-DV1-BH3 polypeptide resulted in a 7.4-fold elevation in the level of caspase-9 (Figure 5A and B). Caspase-3, the final executor of apoptosis, was also regulated by fused TAT-DV1-BH3 polypeptide in a concentration-dependent manner (Figure $5 \mathrm{~A}$ and $\mathrm{B}$ ). There was a $53.3 \%, 92.3 \%$, and $93.3 \%$ decrease in the level of procaspase-3 ( $P<0.001$; Figure $5 \mathrm{~A}$ and $\mathrm{B})$. Taken together, fused TAT-DV1-BH3 polypeptide shows a capability of inducing apoptosis through targeting caspase- 9 and -3 . The proapoptotic effect of fused TAT-DV1-BH3 polypeptide provides an explanation for its anticancer effect. However, the 


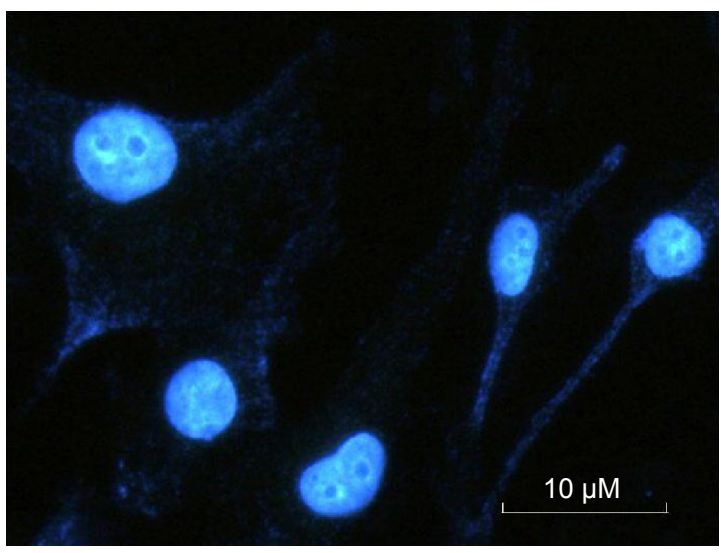

Control

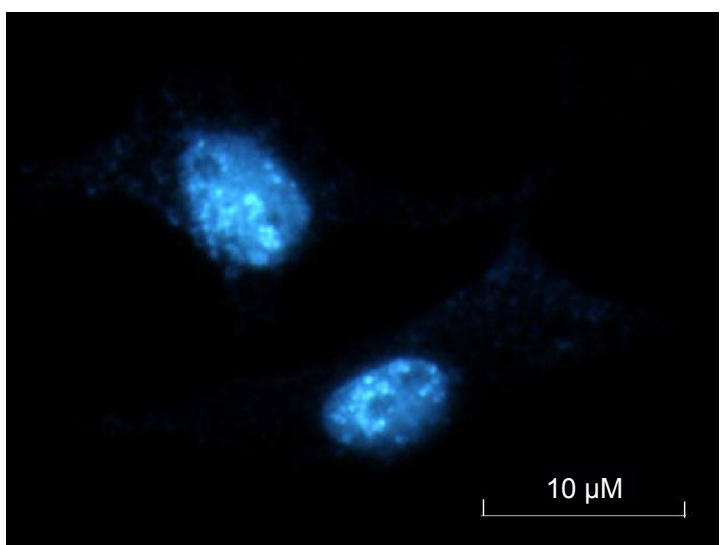

48 hours

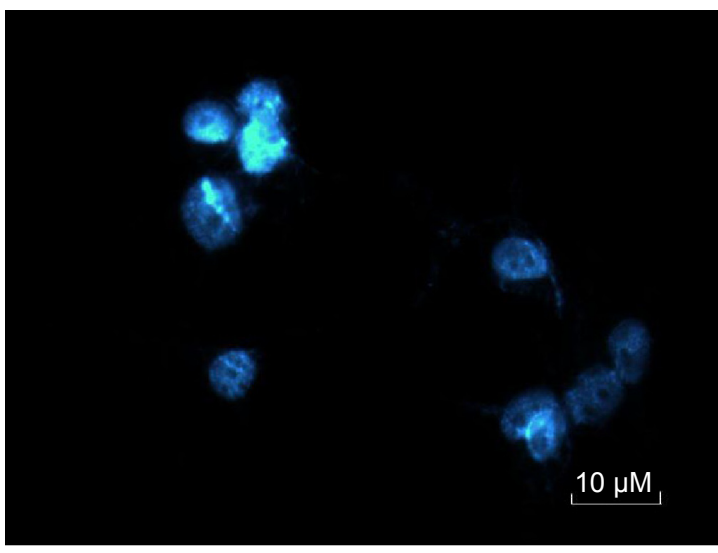

24 hours

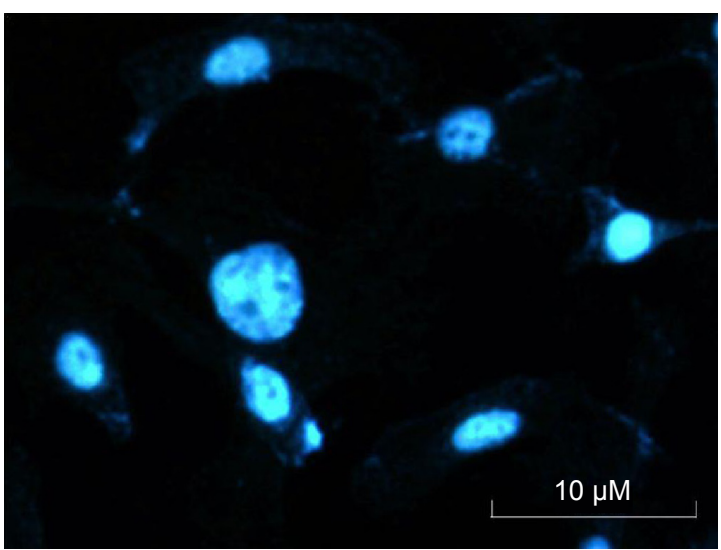

72 hours

Figure 4 The morphology of TAT-DVI-BH3-induced apoptosis in MDA-MB-23I cells.

Notes: MDA-MB-23I cells were treated with $80 \mu \mathrm{M}$ TAT-DVI-BH3 for 0 hour, 24 hours, 48 hours, or 72 hours and the cells were stained with DAPI. The apoptotic morphology was observed using fluorescent microscopy. The control group cells exhibited intact nuclear membranes and clear chromatin, consistent with normal nuclear morphology. After 48-hour treatment, the nuclei exhibited crimpled nuclear membrane and condensed chromatin. After 72-hour treatment, the nuclei exhibited significant membrane breakage, chromatin condensation, and fragmentation.

Abbreviations: $\mathrm{BH}, \mathrm{Bcl}-2$ homology 3; TAT, transactivator of transcription; DAPI, 4,6-diamidino-2-phenylindole.

present study could not exclude the possibility of the involvement of other pathways in the induction of apoptosis.

\section{TAT-DVI-BH3 polypeptide inhibits the migration and invasion of MDA-MB-23 I cells}

Based on the inhibitory effect of TAT-DV1-BH3 on tumor metastasis in nude mice, we further evaluated the effect of TAT-DV1-BH3 on breast cancer cell migration and invasion using cell wound healing assay and transwell assay. The highly metastatic human breast cancer cell line, MDA-MB-231 cells, was employed and treated with fused TAT-DV1-BH3 polypeptide at different concentrations $>48$ hours after cell scratching. TAT-DV1-BH3 polypeptide concentration dependently inhibited the migration of MDA-MB-231 cells (Figure 6A and B). Incubation of cells with $40 \mu \mathrm{M}$ and $80 \mu \mathrm{M}$ of TAT-DV1-BH3 polypeptide remarkably reduced the number of migrated cells $>48$ hours $(P<0.01$ or 0.001 ;
Figure $6 \mathrm{~A}$ and B). Low concentration of TAT-DV1-BH3 polypeptide did not significantly affect the cell migration (Figure 6A and B). We have also performed transwell invasion assay to examine the antimetastasis effect of TAT-DV1-BH3 polypeptide. As shown in Figure 7A and B, TAT-DV1-BH3 polypeptide exhibited a concentration-dependent inhibitory effect on the invasion of MDA-MB-231 cells. There was a $12.2 \%, 63.3 \%(P<0.001)$, and $86.8 \%(P<0.001)$ reduction in invaded cells when treated with TAT-DV1-BH3 polypeptide at $20 \mu \mathrm{M}, 40 \mu \mathrm{M}$, and $80 \mu \mathrm{M}$, compared to the control, respectively (Figure 7B). Taken together, the results indicate that fused TAT-DV1-BH3 polypeptide exerts a potent inhibitory effect on cell migration and invasion, contributing to the antimetastasis effect in vivo.

Furthermore, we investigated the mechanism for the inhibitory effect of TAT-DV1-BH3 polypeptide on migration and invasion of MDA-MB-231. Due to the proposed role of TATDV1-BH3 polypeptide in antagonizing CXCR4, we examined 
A

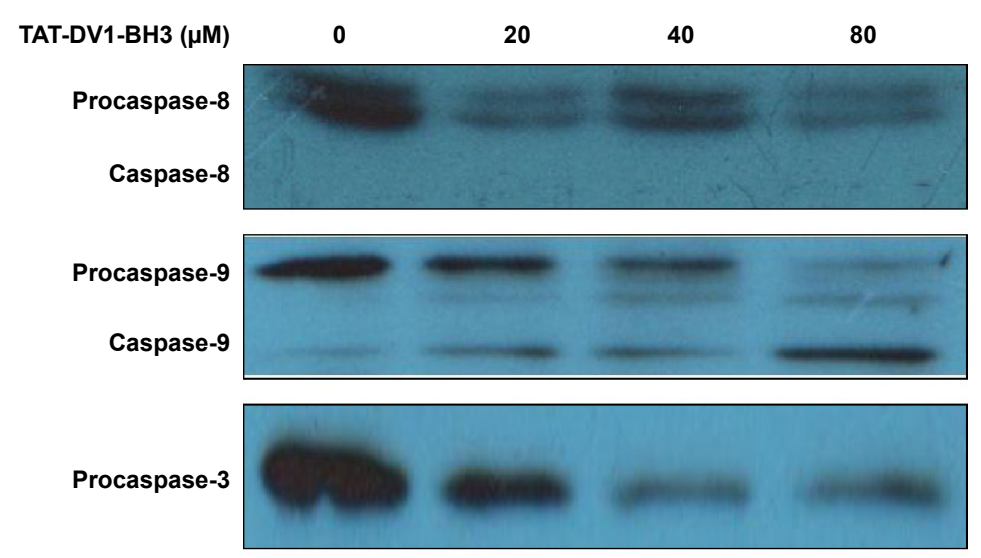

$\beta$-actin

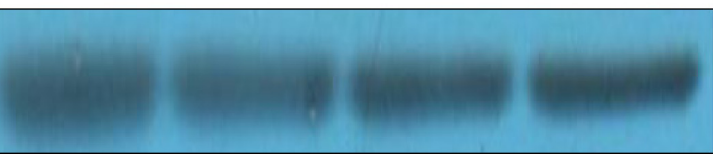

B
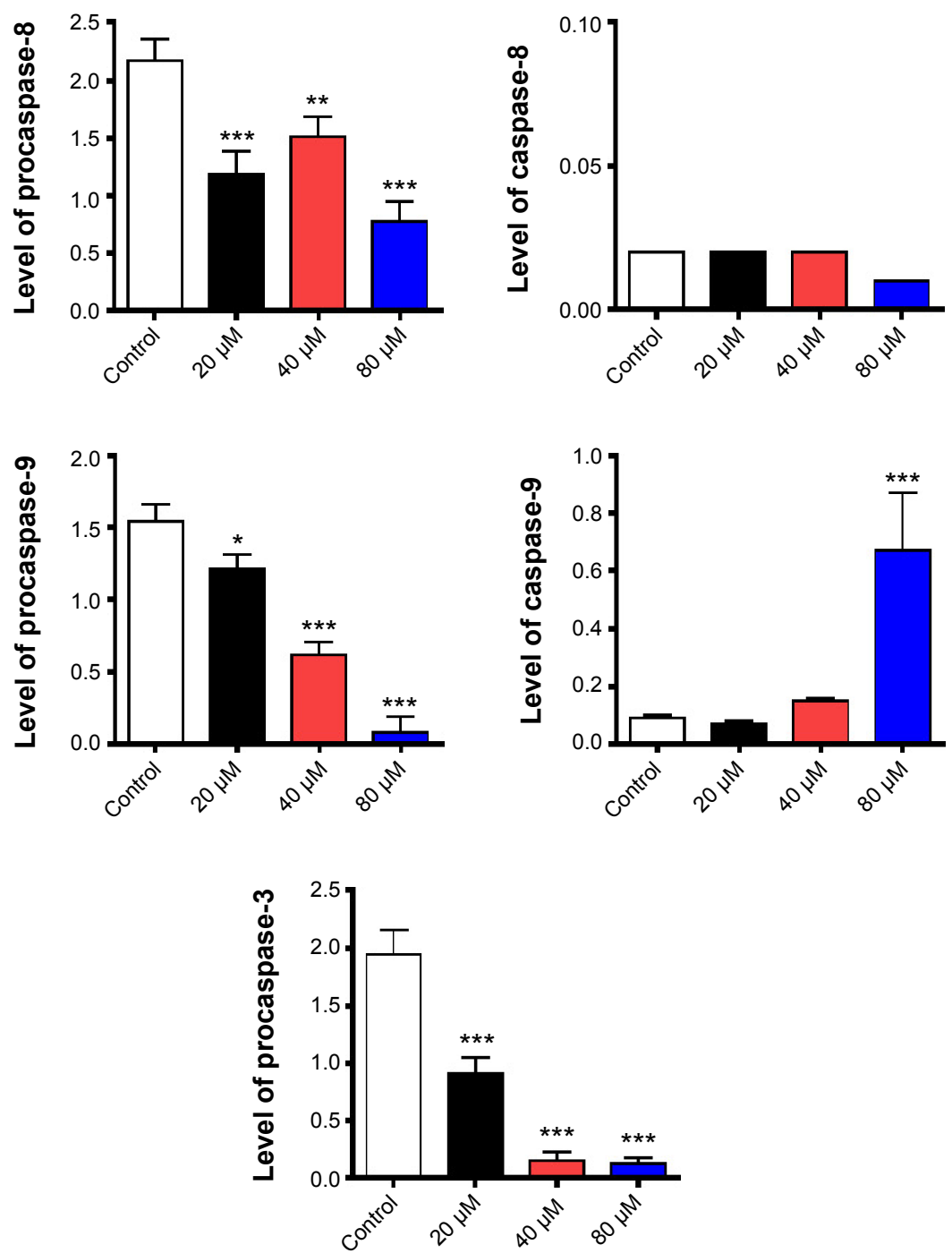

Figure 5 Effect of TAT-DVI-BH3 on the expression of key molecules in the apoptosis.

Notes: MDA-MB-23I cells were treated with TAT-DVI-BH3 at $20 \mu \mathrm{M}, 40 \mu \mathrm{M}$, or $80 \mu \mathrm{M}$ for 72 hours. The expression level of the procaspase-8, -9 , and -3 and active caspase- 8 and -9 was examined using Western blotting assay. (A) Representative blots of procaspase-8, -9 , and -3 and active caspase-8 and -9 . (B) Bar graph showing the relative expression level of procaspase- $8,-9$, and -3 and active caspase- 8 and -9 . $\beta$-Actin acts as the internal control. Data are expressed as mean \pm SD of three independent experiments. $* P<0.05$, $* * P<0.01$, and $* * * P<0.001$ by one-way ANOVA.

Abbreviations: $\mathrm{BH} 3, \mathrm{Bcl}-2$ homology 3; TAT, transactivator of transcription; SD, standard deviation; ANOVA, analysis of variance. 
A

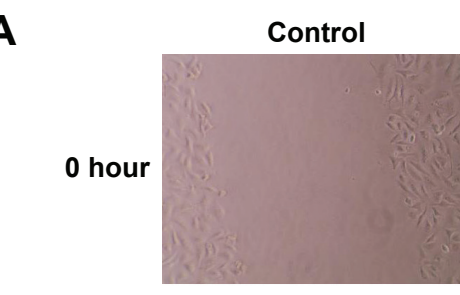

12 hours
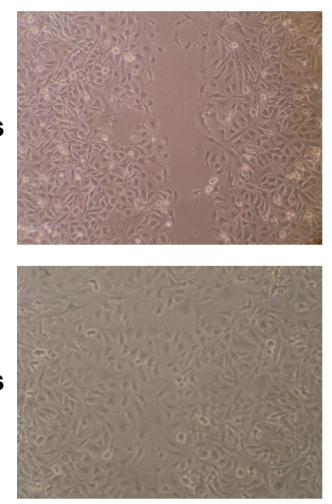

24 hours

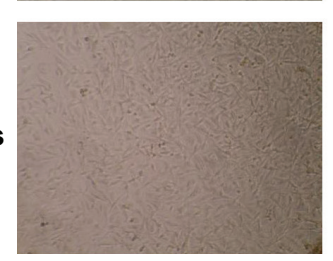

$20 \mu \mathrm{M}$
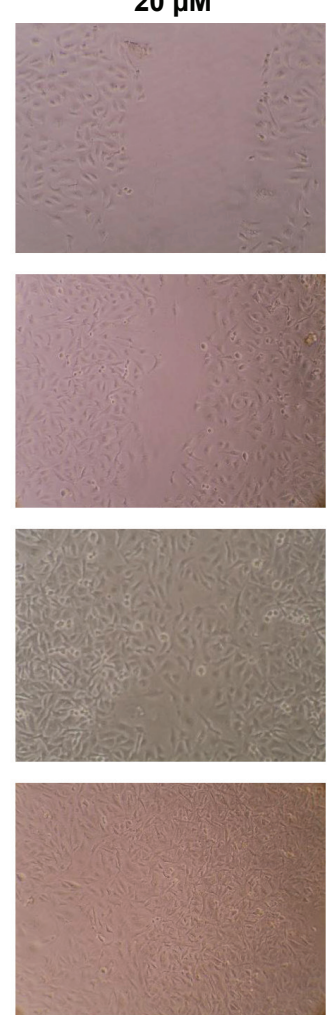

$40 \mu \mathrm{M}$
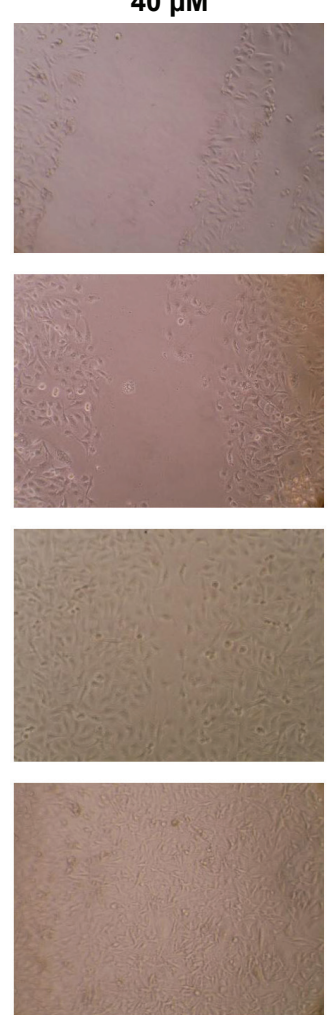

$80 \mu \mathrm{M}$
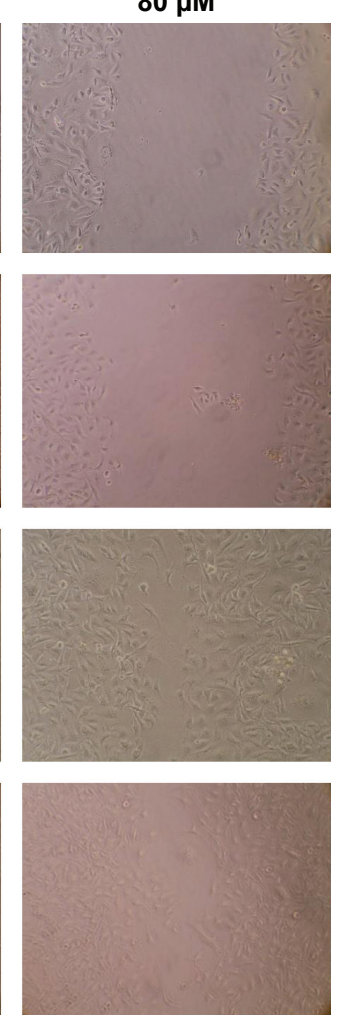

B

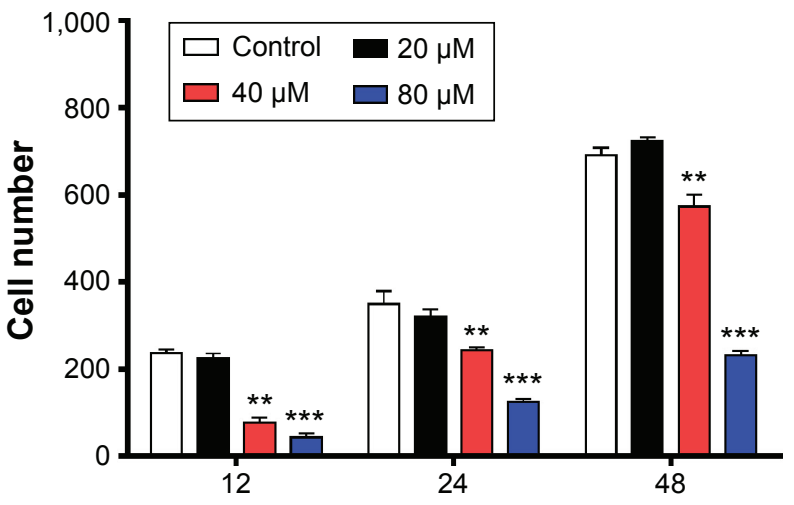

Figure 6 Effect of TAT-DVI-BH3 on the migration of MDA-MB-23I cells.

Notes: The effect of TAT-DVI-BH3 on the migration of MDA-MB-23I cells was examined using cell wound healing assay. Cells were confluent and scratched, then treated with TAT-DVI-BH3 at $20 \mu \mathrm{M}, 40 \mu \mathrm{M}$, or $80 \mu \mathrm{M}$ for 12 hours, 24 hours, or 48 hours. (A) Photos showing the wound healing of MDA-MB-23I cells. (B) Bar graph showing the migrated cells. Data are expressed as mean $\pm S D$ of three independent experiments. ${ }^{*} * P<0.01$ and $* * * P<0.00 I$ by one-way ANOVA. Magnification, I00 $\times$. Abbreviations: $\mathrm{BH} 3, \mathrm{Bcl}-2$ homology 3; TAT, transactivator of transcription; SD, standard deviation; ANOVA, analysis of variance.

the effect of TAT-DV1-BH3 polypeptide on expression of key molecules involved in cell motility and invasion in the CXCR4 signaling pathway. Treatment of cells with TAT-DV1-BH3 polypeptide markedly decreased the expression of PI3K and MMP-9 (Figure 8A and B). In comparison to the control, there was a $31.6 \%, 31.6 \%$, and $68.4 \%$ reduction in the level of PI3K and $61.5 \%, 80.8 \%$, and $84.6 \%$ decrease in the level of MMP-9 when treated with fused TAT-DV1-BH3 polypeptide at $20 \mu \mathrm{M}, 40 \mu \mathrm{M}$, and $80 \mu \mathrm{M}$ (Figure $8 \mathrm{~B}$ ). The results suggest that targeting PI3K and MMP-9 contributes to the antimetastasis effect of fused TAT-DV1-BH3 polypeptide.

\section{TAT-DVI-BH3 polypeptide inhibits tumor growth and metastasis in nude mice}

Due to the potential role of fused polypeptides in antagonizing CXCR4, we first examined the anticancer effect of fused polypeptides in vivo using nude mice. Mice bearing established MDA-MB-231 tumors were treated with PBS, DV1-BH3, TAT-DV1, or TAT-DV1-BH3 once every 2 days for 23 days via intratumoral injection. The tumor size and mass and the formation of metastasis were examined. As shown in Figure 9A-D, the results showed that 

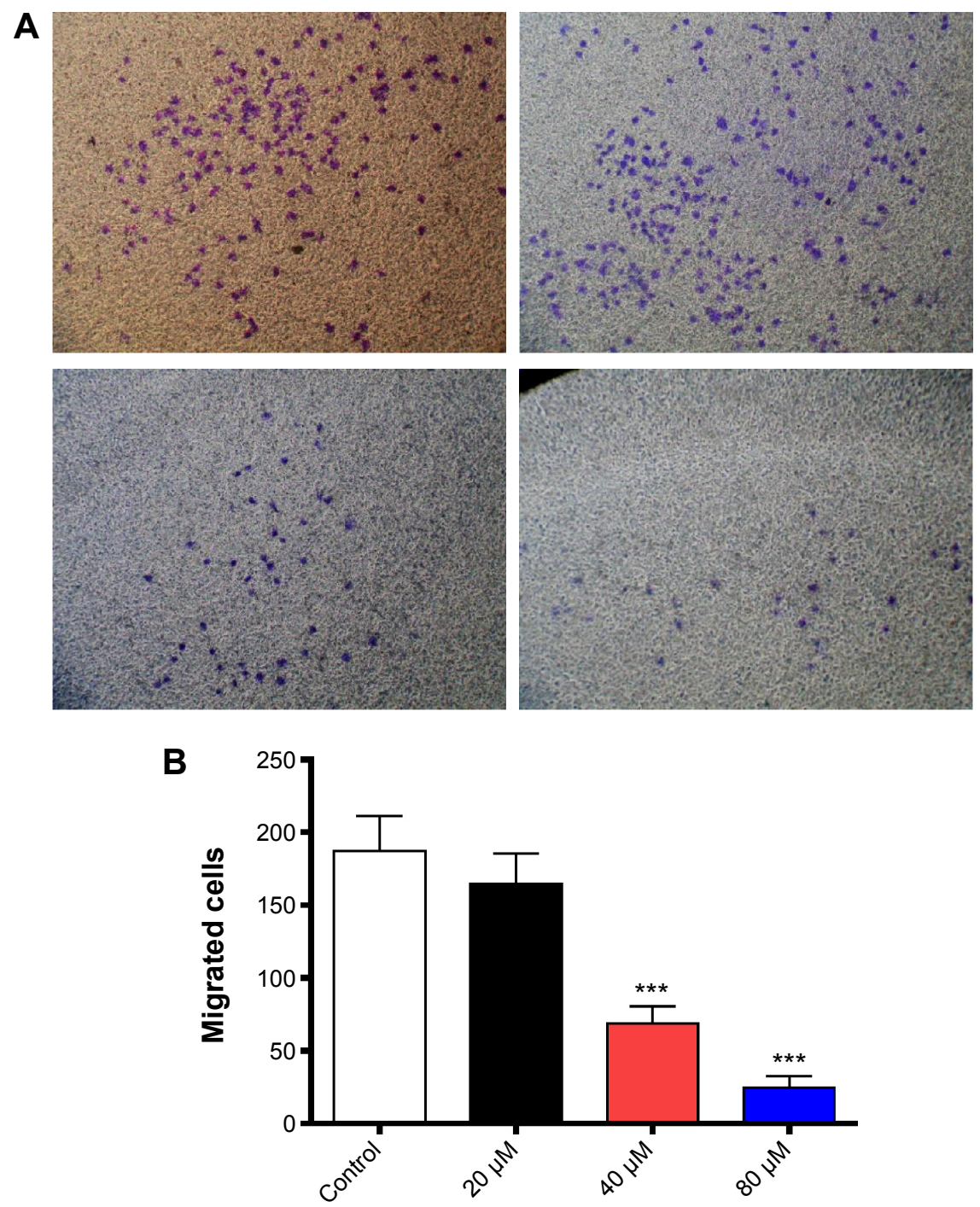

Figure 7 Effect of TAT-DVI-BH3 on the invasion of MDA-MB-23I cells.

Notes: The effect of TAT-DVI-BH3 on the invasion migration of MDA-MB-23I cells was examined using transwell assays. Cells were treated with TAT-DVI-BH3 at $20 \mu \mathrm{M}, 40 \mu \mathrm{M}$, or $80 \mu \mathrm{M}$ for 24 hours. (A) Photos showing the invasion of MDA-MB-23I cells. (B) Bar graph showing the invaded cells. Data are expressed as mean \pm SD of three independent experiments. $* * * P<0.00$ I by one-way ANOVA. Magnification, 100 $\times$.

Abbreviations: $\mathrm{BH} 3, \mathrm{Bcl}-2$ homology 3; TAT, transactivator of transcription; SD, standard deviation; ANOVA, analysis of variance.

TAT-DV1-BH3 inhibited the tumor growth in nude mice $(P<0.05)$. Compared to the vehicle group, there was a marked reduction in the tumor volume when treated with TAT-DV3-BH3 from the 15th day to the 23rd day $(P<0.05$; Figure 9C). Moreover, administration of mice with TATDV3-BH3 led to a decrease in the tumor mass (Figure 9D). There was no significant effect of TAT-DV1-BH3 compared with the others group on tumor size and growth in nude mice $(P<0.05$; Figure $9 \mathrm{C}$ and $\mathrm{D})$.

Following the examination of tumor size and growth, we also performed pathological examination to test the effect of fused polypeptides on tumor metastasis using $\mathrm{H} \& \mathrm{E}$ staining (Figure 10A-D). Mice bearing established MDA-MB-231 tumors were treated with PBS, DV1-BH3, TAT-DV1, or TAT-DV1-BH3. TAT-DV1-BH3 treatment showed a potent inhibitory effect on tumor metastasis to the liver in nude mice with a marked reduction in the metastatic site, compared to the vehicle group (Figure 10A-D). However, DV1-BH3 and TAT-DV1 did not show evident suppressing effect on tumor metastasis in nude mice (Figure 10B and C). Collectively, the results indicate that TAT-DV1-BH3 inhibits the growth and metastasis of breast cancer in nude mice.

\section{Discussion}

Breast cancer remains a major challenge to human health with substantial morbidity and mortality, although there is improvement in the breast cancer therapies. Compelling evidence indicates that the targeted therapy exerts great merits of improved therapeutic effect and reduced side effect in the 

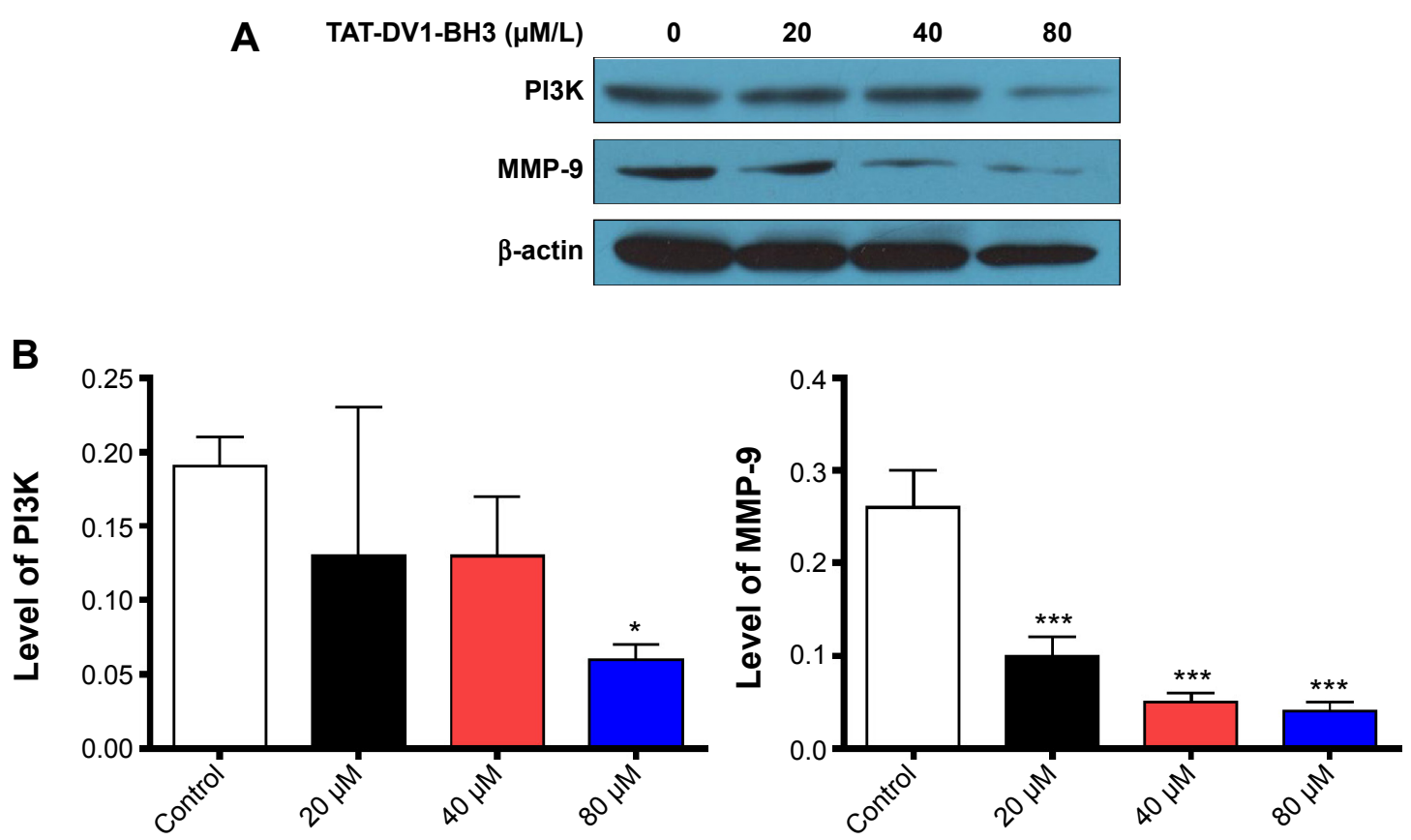

Figure 8 Effect of TAT-DVI-BH3 on the expression of key molecules involved in migration and invasion in the CXCR4 pathway.

Notes: MDA-MB-23I cells were treated with TAT-DVI-BH3 at $20 \mu \mathrm{M}, 40 \mu \mathrm{M}$, or $80 \mu \mathrm{M}$ for 72 hours. The expression level of the PI3K and MMP-9 was examined using Western blotting assay. (A) Representative blots of PI3K and MMP-9. (B) Bar graph showing the relative expression level of PI3K and MMP-9. $\beta$-Actin acts as the internal control. Data are expressed as mean \pm SD of three independent experiments. $* P<0.05$ and $* * * P<0.00$ I by one-way ANOVA.

Abbreviations: $\mathrm{BH} 3, \mathrm{Bcl}-2$ homology 3; TAT, transactivator of transcription; CXCR4, CXC chemokine receptor 4; SD, standard deviation; ANOVA, analysis of variance.

A

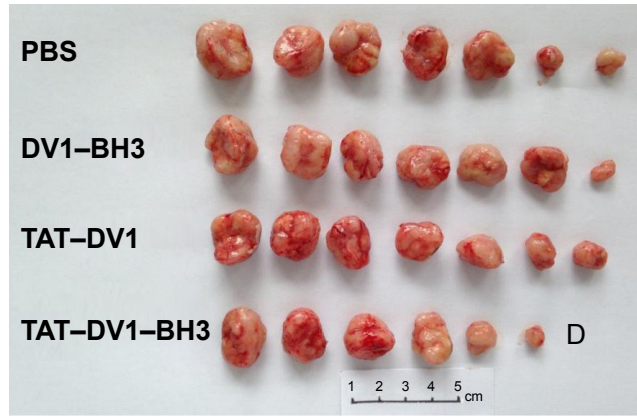

C

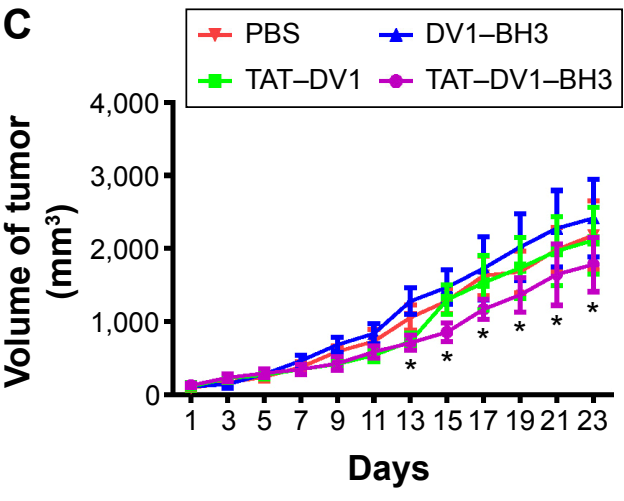

B
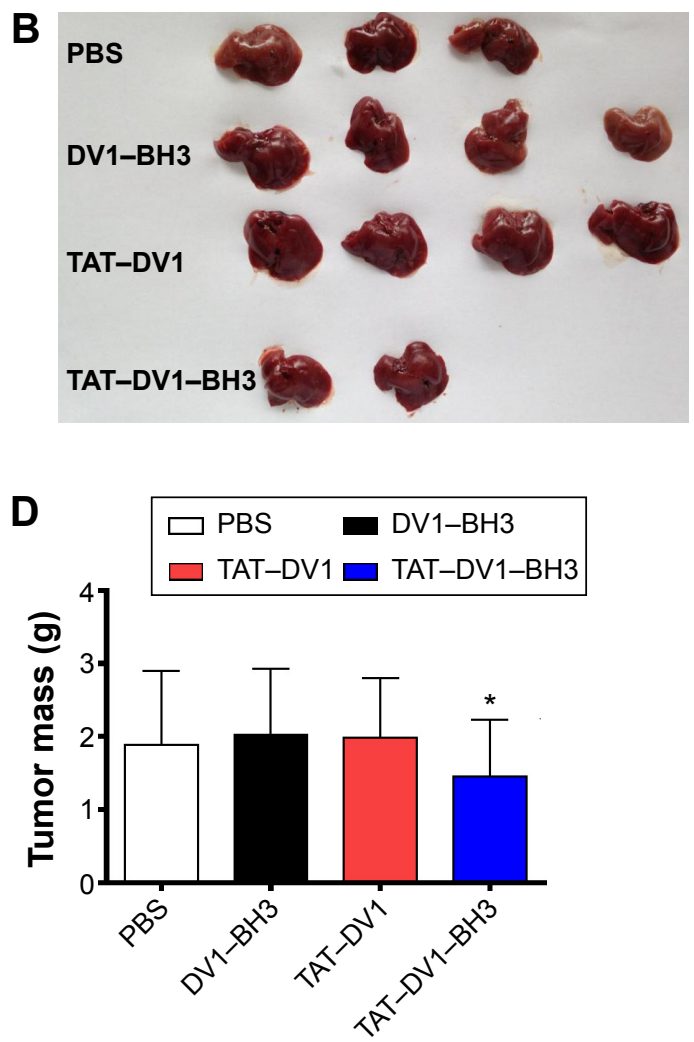

Figure 9 Effect of DVI-BH3, TAT-DVI, and TAT-DVI-BH3 on tumor growth and metastasis in nude mice.

Notes: Nude mice were dosed with DVI-BH3, TAT-DVI, and TAT-DVI-BH3 for 23 days ( $\mathrm{n}=7$ ). (A) Alignment of tumor of each group after 23-day treatment. "D” in figure stands for tumor disappeared. (B) Alignment of metastatic liver after 23-day treatment. (C) Bar graph showing the tumor volume in mice treated with PBS, DVI-BH3, TAT-DVI, or TAT-DVI-BH3. (D) Bar graph showing the tumor mass on the 23rd day. Data are expressed as mean \pm SD. $* P<0.05$ by one-way ANOVA.

Abbreviations: $\mathrm{BH}, \mathrm{Bcl}-2$ homology 3; TAT, transactivator of transcription; PBS, phosphate-buffered saline; SD, standard deviation; ANOVA, analysis of variance. 

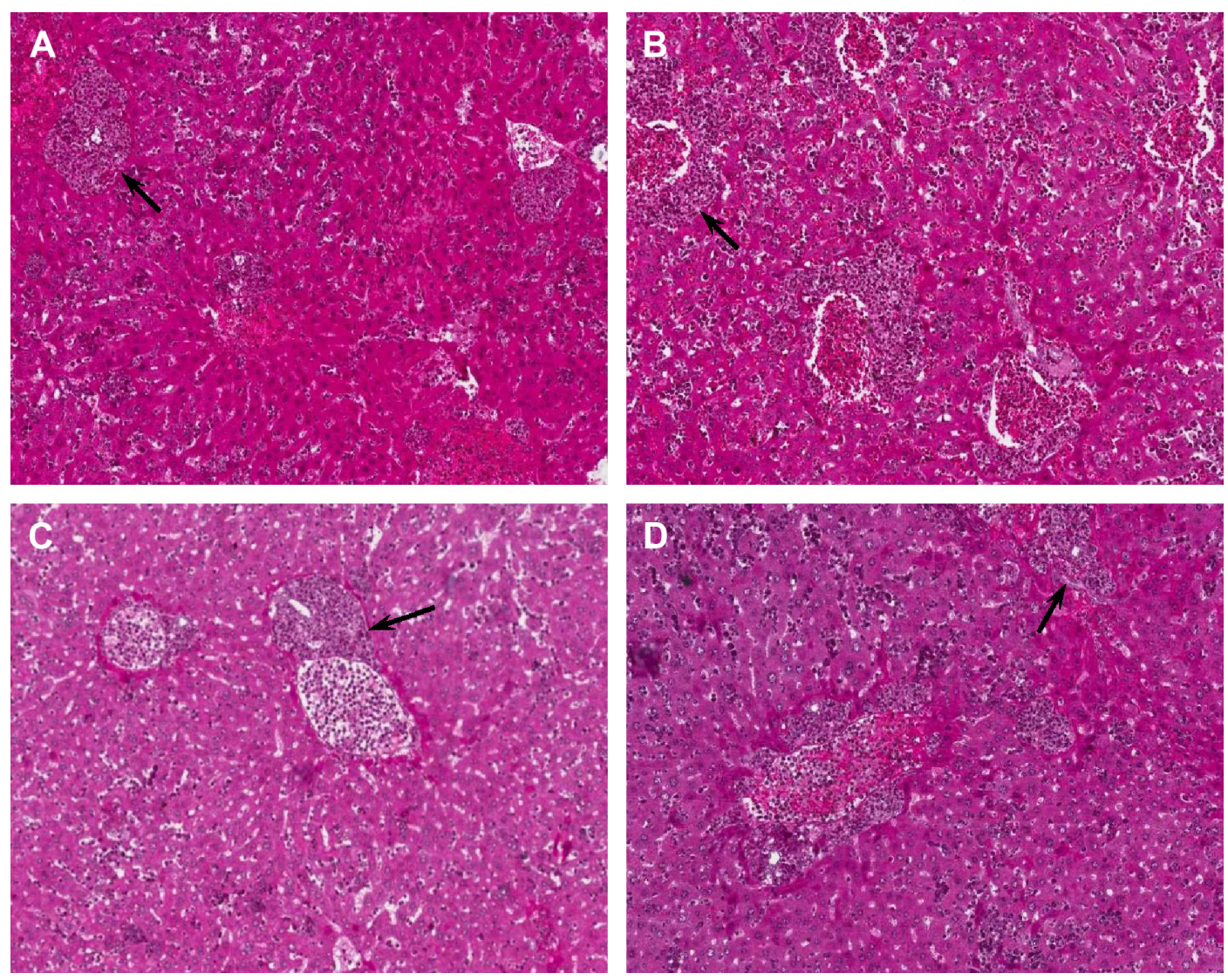

Figure $10 \mathrm{HE}$ staining of liver metastases.

Notes: Nude mice were dosed with DVI-BH3, TAT-DVI, and TAT-DVI-BH3 for 23 days ( $n=7$ ). Images representing HE-stained liver metastases in the PBS (A), DVI-BH3 (B), TAT-DVI (C), and TAT-DVI-BH3 (D) groups. Arrows indicate tumor metastases. Magnification, I00×.

Abbreviations: $\mathrm{HE}$, hematoxylin and eosin; $\mathrm{BH} 3, \mathrm{Bcl}-2$ homology 3; TAT, transactivator of transcription; PBS, phosphate-buffered saline.

treatment of breast cancer in clinical practice ${ }^{18,19}$ and that CXCR4 has been proposed to be a promising therapeutic target for breast cancer treatment. ${ }^{20-22}$ In the present study, we have shown that the fused TAT-DV1-BH3 polypeptide exhibits potent anticancer effects in mice bearing established MDA-MB-231 tumors, with marked inhibitory effect on breast cancer cell invasion and metastasis and remarkable proapoptotic effects. The fused TAT-DV1-BH3 polypeptide inhibits the growth of tumor cells through BH3-mediated apoptosis and prevents breast cancer cell invasion and metastasis via DV1 inhibition of the SDF-1/CXCR4 signaling pathway.

Targeted fused polypeptides are an emerging hotspot in targeted therapy for breast cancer. ${ }^{23,24}$ There are a number of studies on the anticancer effect of targeted fused polypeptides in the treatment of breast cancer, including targeting the conserved transmembrane domain of human epidermal growth factor receptors, ${ }^{25-29}$ glucose-regulated protein $78,{ }^{30}$ transferrin receptor, ${ }^{31}$ and $\mathrm{p} 53 .{ }^{32}$ These targeted fused polypeptides exhibited a potent cell death inducing effect on tumor cells and a considerable suppressing effect on tumor growth and metastasis, indicating that the targeted fused polypeptide represents a promising targeted therapy strategy. Previously, our group also designed a fused TAT-DV3-BH3 polypeptide that included a protein transduction peptide from HIV-1 transactivating factor (TAT), a targeted sequence DV3 directing CXCR4 binding, and a BH3 effector sequence from only one domain of the p53 upregulated modulator of apoptosis. This fused polypeptide can specifically inhibit the growth of human colon cancer cells by inducing cell apoptosis in vitro. ${ }^{7}$ Furthermore, the fused polypeptide can significantly repress the growth of human colon tumor in a nude mouse model. ${ }^{7}$ The results indicate that the fused TAT-DV3-BH3 polypeptide possesses anticancer effect.

It has been reported that $\mathrm{V} 1$ is a synthesized polypeptide antagonizing CXCR4 and inhibiting the replication of HIV. ${ }^{15}$ DV1 possesses the same amino acids sequence as V1, but it is composed of D-configuration amino acids. DV1 can bind to CXCR4 with high affinity and can more potently inhibit the replication capability of HIV-1 with CXCR $4^{+}$ 
T-cell. Therefore, DV1 is an ideal CXCR4 antagonist because of the D-configuration amino acids; it can resist protease-mediated degradation in vivo; and it exhibits greater potential in clinical applications than that of V1. ${ }^{13,15,33,34} \mathrm{DV} 1$ binds to CXCR4 resulting in the suppression of CXCR4 signaling pathway and metastasis mediated by SDF-1/ CXCR4. Besides, TAT was used to ensure the entry of the fused polypeptide into cells efficiently. Therefore, the fused TAT-DV1-BH3 polypeptide was speculated to show potent anticancer effect. Indeed, the results indicated that the fused TAT-DV1-BH3 polypeptide exhibited substantial antitumor effects. The polypeptide inhibited the growth of MDA-MB-231 and MCF-7 cells and inhibited the invasion and metastasis of the highly metastatic breast cancer cell line MDA-MB-231. The fused TAT-DV1-BH3 polypeptide inhibited the growth of tumor cells through BH3-mediated apoptosis and prevented invasion and metastasis through DV1 inhibition of the SDF-1/CXCR4 pathway in vitro and in vivo. Tumor metastasis is a key factor compromising the therapeutic effect and prognosis of solid tumor in clinical practice. ${ }^{35}$ Therefore, bifunctional fused polypeptides that can inhibit tumor growth and metastasis is a research goal.

In comparison to our previous study, ${ }^{7}$ we replaced DV3 with DV1 in the fused polypeptide. The TAT-DV1-BH3 polypeptide not only can exhibit superior targeting but also can inhibit the biological functions of CXCR4, including tumor invasion and migration. The fused TAT-DV1-BH3 polypeptide dose-dependently inhibited the growth of MDAMB-231 and MCF-7 breast cancer cells but not the growth of the nontumorigenic HEK-293 cells. Moreover, two control polypeptides did not significantly inhibit the growth of the two breast cancer lines. These results indicated that the fused TAT-DV1-BH3 polypeptide could selectively inhibit breast cancer cell lines and that TAT-DV1 and DV1-BH3 exhibited no growth inhibition of tumor cells and nontumor cells. Flow cytometry and laser confocal microscopy indicated that the fused polypeptides with TAT could enter cells efficiently; DV1-BH3 without TAT exhibited very low transfection efficiency in these three cell lines. These results indicated that only the fused polypeptides with TAT could enter cells, demonstrating that TAT possesses strong cellular transduction abilities. TAT-DV1 did not inhibit the growth of cells but could carry some material (such as polypeptides) to effectively enter cells expressing high levels of CXCR4. Thus, TAT-DV1 could be used as an efficient targeting agent for anticancer drug delivery. Our confocal laser experiments also revealed that the fused polypeptide TAT-DV1-BH3 mainly colocalized to the mitochondria, which indicated that the fused polypeptide might induce tumor cell apoptosis through a mitochondrial pathway and also inhibit the growth of tumor cells. Indeed, the DAPI staining and Western blotting assay showed that TAT-DV1-BH3 could induce MDA-MB-231 apoptosis with the involvement of mitochondrial pathway. Furthermore, our results also suggested that TAT-DV1-BH3 could dose dependently inhibit the migration and invasion of the highly metastatic human breast cancer cell line MDA-MB-231 through the inhibition of CXCR4 function and inhibited the migration and invasion of tumor cells. The fused TAT-DV1-BH3 polypeptide inhibited tumor growth and decreased liver metastasis in nude mouse model of breast cancer. Our findings suggest that the fused TAT-DV1-BH3 polypeptide has great potential in the treatment of breast cancer, with the merits of selectively targeting CXCR4, high transduction efficiency, and potent apoptosis-inducing and metastasis-suppressing effects.

\section{Conclusion}

In summary, the present study demonstrated that the fused TAT-DV1-BH3 polypeptide exerted an integrative effect of each component, ensuring that the fused polypeptide could efficiently enter cells and, specifically targeting CXCR4, potently inhibit the growth of breast cancer cells by inducing apoptosis via the mitochondrial pathway. Furthermore, the fused TAT-DV1-BH3 polypeptide could inhibit the expression of PI3K and MMP-9 and inhibit the migration and invasion of the highly metastatic breast cancer cell line MDA-MB-231 via suppressing CXCR4-mediated signaling pathways. This study provides evidence for improving targeted polypeptides in the treatment of breast cancer and suggests that TAT-DV1 can be used as an efficient targeting delivery carrier for anticancer drugs.

\section{Acknowledgments}

This work was supported by National Natural Science Foundation of China (No 81071853) and College Research Institutions of Dongguan City Science and Technology Projects (No 201010815210).

\section{Disclosure}

The authors report no conflicts of interest in this work.

\section{References}

1. Bray F, Jemal A, Grey N, Ferlay J, Forman D. Global cancer transitions according to the human development index (2008-2030): a populationbased study. Lancet Oncol. 2012;13(8):790-801.

2. Ferlay J, Soerjomataram I, Ervik M, et al. GLOBOCAN 2012 v1.0, Cancer Incidence and Mortality Worldwide: IARC CancerBase No 11 [Internet]. Lyon, France: International Agency for Research on Cancer; 2013. 
3. Alvarez RH, Valero V, Hortobagyi GN. Emerging targeted therapies for breast cancer. J Clin Oncol. 2010;28(20):3366-3379.

4. Perez EA, Spano JP. Current and emerging targeted therapies for metastatic breast cancer. Cancer. 2012;118(12):3014-3025.

5. Ghobrial IM, Witzig TE, Adjei AA. Targeting apoptosis pathways in cancer therapy. CA Cancer J Clin. 2005;55(3):178-194.

6. Bai L, Wang S. Targeting apoptosis pathways for new cancer therapeutics. Annu Rev Med. 2014;65:139-155.

7. Liu Y, Li Y, Wang H, et al. BH3-based fusion artificial peptide induces apoptosis and targets human colon cancer. Mol Ther. 2009;17(9): $1509-1516$.

8. Zheng H, Kang Y. Multilayer control of the EMT master regulators. Oncogene. 2014;33(14):1755-1763.

9. Lamouille S, Xu J, Derynck R. Molecular mechanisms of epithelialmesenchymal transition. Nat Rev Mol Cell Biol. 2014;15(3):178-196.

10. Zlotnik A, Yoshie O. Chemokines: a new classification system and their role in immunity. Immunity. 2000;12(2):121-127.

11. Balkwill F. The significance of cancer cell expression of the chemokine receptor CXCR4. Semin Cancer Biol. 2004;14(3):171-179.

12. Engl T, Relja B, Marian D, et al. CXCR4 chemokine receptor mediates prostate tumor cell adhesion through alpha 5 and beta3 integrins. Neoplasia. 2006;8(4):290-301.

13. Snyder EL, Saenz CC, Denicourt C, et al. Enhanced targeting and killing of tumor cells expressing the CXC chemokine receptor 4 by transducible anticancer peptides. Cancer Res. 2005;65(23):10646-10650.

14. Müller A, Homey B, Soto H, et al. Involvement of chemokine receptors in breast cancer metastasis. Nature. 2001;410(6824):50-56.

15. Zhou N, Luo Z, Luo J, et al. Exploring the stereochemistry of CXCR4peptide recognition and inhibiting HIV-1 entry with D-peptides derived from chemokines. J Biol Chem. 2002;277(20):17476-17485.

16. Hao H, Dong Y, Bowling MT, Gomez-Gutierrez JG, Zhou HS, McMasters KM. E2F-1 induces melanoma cell apoptosis via PUMA up-regulation and Bax translocation. BMC Cancer. 2007;7:24.

17. Gong Y, Deng-Bin W. Comparison of orthotopically implanted mouse models of primary breast cancer established by difierent methods. J Shanghai Jiaotong Univ. 2007;27(7):818-822.

18. Aggarwal S. Targeted cancer therapies. Nat Rev Drug Discov. 2010; $9(6): 427-428$

19. Higgins MJ, Baselga J. Targeted therapies for breast cancer. J Clin Invest. 2011;121(10):3797-3803.

20. Clezardin P. Therapeutic targets for bone metastases in breast cancer. Breast Cancer Res. 2011;13(2):207.

21. Ribas R, Ghazoui Z, Gao Q, et al. Identification of chemokine receptors as potential modulators of endocrine resistance in oestrogen receptorpositive breast cancers. Breast Cancer Res. 2014;16(5):447.
22. Liang S, Peng X, LiX, et al. Silencing of CXCR4 sensitizes triple-negative breast cancer cells to cisplatin. Oncotarget. 2015;6(2):1020-1030.

23. Ahmad ZA, Yeap SK, Ali AM, Ho WY, Alitheen NB, Hamid M. scFv antibody: principles and clinical application. Clin Dev Immunol. 2012; 2012:980250

24. Fagbohun OA, Bedi D, Grabchenko NI, Deinnocentes PA, Bird RC, Petrenko VA. Landscape phages and their fusion proteins targeted to breast cancer cells. Protein Eng Des Sel. 2012;25(6):271-283.

25. Hart MR, Su HY, Broka D, Goverdhan A, Schroeder JA. Inactive ERBB receptors cooperate with reactive oxygen species to suppress cancer progression. Mol Ther. 2013;21(11):1996-2007.

26. Kornberger P, Skerra A. Sortase-catalyzed in vitro functionalization of a HER2-specific recombinant Fab for tumor targeting of the plant cytotoxin gelonin. MAbs. 2014;6(2):354-366.

27. Wilkie S, van Schalkwyk MC, Hobbs S, et al. Dual targeting of ErbB2 and $\mathrm{MUC1}$ in breast cancer using chimeric antigen receptors engineered to provide complementary signaling. J Clin Immunol. 2012; 32(5):1059-1070

28. Du YJ, Lin ZM, Zhao YH, et al. Stability of the recombinant antierbB2 scFv-Fcinterleukin2 fusion protein and its inhibition of HER2 overexpressing tumor cells. Int J Oncol. 2013;42(2):507-516.

29. Thakur M, Mergel K, Weng A, et al. Targeted tumor therapy by epidermal growth factor appended toxin and purified saponin: an evaluation of toxicity and therapeutic potential in syngeneic tumor bearing mice. Mol Oncol. 2013;7(3):475-483.

30. Miao YR, Eckhardt BL, Cao Y, et al. Inhibition of established micrometastases by targeted drug delivery via cell surface-associated GRP78. Clin Cancer Res. 2013;19(8):2107-2116.

31. Ye Q, Hu H, Wang Z, et al. Generation and functional characterization of the anti-transferrin receptor single-chain antibody-GAL4 (TfRscFvGAL4) fusion protein. BMC Biotechnol. 2012;12:91.

32. Mossalam M, Matissek KJ, Okal A, Constance JE, Lim CS. Direct induction of apoptosis using an optimal mitochondrially targeted p53. Mol Pharm. 2012;9(5):1449-1458.

33. Luo Z, Fan X, Zhou N, et al. Structure-function study and anti-HIV activity of synthetic peptide analogues derived from viral chemokine vMIP-II. Biochemistry. 2000;39(44):13545-13550.

34. Zhou N, Luo Z, Luo J, Hall JW, Huang Z. A novel peptide antagonist of CXCR4 derived from the N-terminus of viral chemokine vMIP-II. Biochemistry. 2000;39(13):3782-3787.

35. Weigelt B, Peterse JL, van't Veer LJ. Breast cancer metastasis: markers and models. Nat Rev Cancer. 2005;5(8):591-602.
Drug Design, Development and Therapy

\section{Publish your work in this journal}

Drug Design, Development and Therapy is an international, peerreviewed open-access journal that spans the spectrum of drug design and development through to clinical applications. Clinical outcomes, patient safety, and programs for the development and effective, safe, and sustained use of medicines are a feature of the journal, which

\section{Dovepress}

has also been accepted for indexing on PubMed Central. The manuscript management system is completely online and includes a very quick and fair peer-review system, which is all easy to use. Visit http://www.dovepress.com/testimonials.php to read real quotes from published authors. 